University of South Florida

DIGITAL COMMONS

Digital Commons @ University of

@ UNIVERSITY OF SOUTH FLORIDA

South Florida

4-7-2006

\title{
GENDER DIFFERENCES IN AGE OF ONSET FOR DELINQUENCY:RISK FACTORS AND CONSEQUENCES
}

Laura M. Gulledge

University of South Florida

Follow this and additional works at: https://digitalcommons.usf.edu/etd

Part of the American Studies Commons, and the Criminology and Criminal Justice Commons

\section{Scholar Commons Citation}

Gulledge, Laura M., "GENDER DIFFERENCES IN AGE OF ONSET FOR DELINQUENCY:RISK FACTORS AND CONSEQUENCES" (2006). USF Tampa Graduate Theses and Dissertations.

https://digitalcommons.usf.edu/etd/3828

This Thesis is brought to you for free and open access by the USF Graduate Theses and Dissertations at Digital Commons @ University of South Florida. It has been accepted for inclusion in USF Tampa Graduate Theses and Dissertations by an authorized administrator of Digital Commons @ University of South Florida. For more information, please contact digitalcommons@usf.edu. 


\title{
GENDER DIFFERENCES IN AGE OF ONSET FOR DELINQUENCY: RISK FACTORS AND CONSEQUENCES
}

\author{
by
}

\section{LAURA M. GULLEDGE}

A thesis submitted in partial fulfillment of the requirements for the degree of

Masters of Arts

Department of Criminology

College of Arts and Sciences

University of South Florida

Major Professor: John K. Cochran, Ph.D.

Christine S. Sellers, Ph.D.

Shayne Jones, Ph.D.

Date of Approval:

April 7, 2006

Keywords: life-course, developmental, predictors, females, early

๑) Copyright 2006, Laura M. Gulledge 


\section{Dedication}

This work is dedicated to four very dear people. First and foremost, this manuscript is dedicated to my wonderful husband, Richard Gulledge. You have shown me an abundance of love and support throughout this entire process. Your belief in me kept me going even when I did not believe in myself. Secondly, I owe tremendous thanks to my incredible parents, Ed and Sandy Thomason. I am where I am today because of your guidance, patience, and unconditional love. You have both made so many sacrifices for me and I will be forever grateful. Finally, this thesis is dedicated to the loving memory of my grandfather, John F. Messiner, who instilled in me a love of learning that will always be a part of me. 


\section{Acknowledgments}

There are many thanks in order to those who have assisted in making this manuscript possible. First, I owe my deepest gratitude to my Major Professor, Dr. John Cochran. You provided me with countless hours of counsel, direction, knowledge, and support. Thank you for always pushing me to reach the highest of standards. I would also like to thank Dr. Christine Sellers and Dr. Shayne Jones, who both gave of their time and expertise to make this work the best it could be. Thank you for all of your encouragement and suggestions. Additionally, I would like to thank Dr. Chris Sullivan for his endless, patient assistance. I would also like to recognize Dr. Chris Gibson for enabling me to pursue this topic. Thank you to all of the others that have offered much appreciated feedback and moral support, including: Dr. Denise Paquette-Boots, Lisa Murphy, Kristina Childs, and Sandy Thomason. 
Table of Contents

List of Tables $\quad$ ii

Abstract

$\begin{array}{lll}\text { Chapter One } \quad \text { Introduction } & 1\end{array}$

Chapter Two Developmental / Life-Course Criminology $\quad 4$

$\begin{array}{lr}\text { Theoretical Concepts } & 8\end{array}$

Theoretical Importance 9

Theoretical Evolution $\quad 10$

Early Antisocial Behavior $\quad 12$

Theoretical Perspective of Early Onset $\quad 13$

$\begin{array}{ll}\text { Male Studies } & 14\end{array}$

Female Studies $\quad 17$

$\begin{array}{ll}\text { Hypotheses } & 19\end{array}$

Chapter Three $\quad$ Research Design and Methodology 21

Dependent Variables 23

Independent Variables $\quad 24$

Analytic Plan 30

Chapter Four $\quad$ Results 33

Modeling Age of First Arrest $\quad 35$

Comparing Across Means 36

Modeling "Early" Onset of Arrest in Males and Females 37

Modeling "Early" Onset as a Predictor of Frequency of Arrest by Gender 41

Chapter Five $\quad$ Conclusion and Discussion 44

$\begin{array}{ll}\text { References } & 55\end{array}$

$\begin{array}{ll}\text { Appendices } & 65\end{array}$

$\begin{array}{ll}\text { Appendix A } & 66\end{array}$

$\begin{array}{ll}\text { Appendix B } & 67\end{array}$

Appendix C $\quad 69$

$\begin{array}{ll}\text { Appendix D } & 70\end{array}$

$\begin{array}{ll}\text { Appendix E } & 71\end{array}$

$\begin{array}{ll}\text { Appendix F } & 72\end{array}$

$\begin{array}{ll}\text { Appendix G } & 73\end{array}$

$\begin{array}{ll}\text { Appendix } \mathrm{H} & 74\end{array}$ 
List of Tables

Table 1. Description of the Data

Table 2. Age of First Arrest $\quad 34$

Table 3. Ordinary Least Squares Regression Predicting Age of First Arrest 36

Table 4a. Mean Comparisons by Age and Gender 38

Table 4b. Significant Differences in Individual Risk Factors by Gender 39

Table 5. Logistic Regression Predicting Early Onset of Arrest by Gender 41

Table 6. Negative Binomial Regression Predicting Frequency of Arrest by Gender 43 


\title{
GENDER DIFFERENCES IN AGE OF ONSET FOR DELINQUENCY: RISK FACTORS AND CONSEQUENCES
}

\author{
Laura M. Gulledge
}

\begin{abstract}
The age of onset of delinquency has long been viewed as a primary indicator for further delinquency and criminality. However, studies on the risk factors for onset, age of onset, and future delinquency have focused predominantly on males. The purpose of this study was to explore gender differences and similarities in risk factors for onset and frequency of arrest. The data used in these analyses were from a longitudinal study, Pathways to Adulthood: A Three Generational Urban Study, 1960-1994. Sixty-six percent $(\mathrm{N}=1,758)$ of the eligible children completed the final survey. Of these children, only 515 were used in this particular study because they had documented ages of first arrest. It is hypothesized that 1) female "early" onset occurs at a later age from that of male "early" onset, 2) risk factors predictive of early onset will differ across gender, and 3) "early" onset in females will be predictive of frequency of subsequent arrests.

With these data, the author uses OLS regression, logistic regression, and negative binomial regression to evaluate these hypotheses regarding age of onset, risk factors for onset, and frequency of arrest. Insufficient evidence was found to support the hypotheses of the current study. A discussion of the findings, as well as implications and calls for future research are discussed.
\end{abstract}




\section{Introduction}

In the fields of both criminology and psychology, the age of onset of delinquency and antisocial behavior has been viewed as a primary indicator for further delinquency and criminality. However, the relationship between earlier onset and future delinquency and crime has been primarily limited to studies of males (Piquero and Chung, 2001). Traditionally, female delinquency has been disregarded and underestimated (ChesneyLind and Okamoto, 2001). Most theories of delinquency are based solely on male children and adolescents and very rarely is any consideration given to whether deviance in females differs (Storvoll and Wichstrom, 2002). Females make up a smaller grouping of detained and adjudicated juvenile delinquents compared to males, yet female rates of delinquency have steadily increased over the past several years (McCabe, Lansing, Garland, \& Hough, 2002). Increases in female arrests markedly surpassed those of males for most of the last decade (Bureau of Justice Statistics, 1999).

Despite these increases, research on the age of onset, the risk factors for onset, and later criminality, as stated above, have focused almost entirely on males. Female populations have been excluded from delinquency studies, as most believe that delinquency in females is only a small variation from delinquency in males (Hoyt and Scherer, 1998). Because of this, it is very difficult to generalize any empirical findings discovered about males to females (McCabe et al, 2002). However, males and females are not similar populations and findings about males can not be assumed to also hold true for females. In addition, some studies have found that early-onset in females is non- 
existent (Silverthorn and Frick, 1999), or very rare compared to that of later onset delinquency (Moffitt, 2001).

The purpose of this study is to explore gender differences in the age of onset, risk factors for onset, and the effects of early onset on the frequency of arrest. Three interrelated questions regarding female onset of delinquency include (1) whether or not there is evidence of early onset of delinquency in females and, if so, at what age this occurs and if this age differs from males; (2) if there are similar or different factors that predict early onset in males and females; and, (3) if an early age of onset is related to frequency of arrest in females. The data employed to examine these questions came from Hardy and Shapiro's study, Pathways to Adulthood: A Three Generational Urban Study, 1960-1994: [Baltimore, Maryland]. Ordinary Least Squares regression, logistic regression, and negative binomial regression analyses are used to evaluate the research questions regarding age of onset, risk factors for onset, and frequency of arrest.

Chapter Two offers a brief history of developmental and/or life-course research. Definitions, generally accepted conclusions, and central focuses of life-course study are explained. A literature review of several major life-course theories is also provided. The current body of research related to early onset in males is then reviewed. The lack of study in the field regarding male and female differences as they relate to onset, risk factors for onset, and offending is explained. The few studies relating to female early onset, as well as how their findings compare to male related studies, are discussed. Finally, the hypotheses for this study are derived from the reviewed literature.

Chapter Three provides an overview of the methods used in the current study. Characteristics of the sample are described. The first outcome measure in the current 
study is age of first arrest, or the age in years that the respondent was first arrested, booked, or charged by an authority of the law. Independent variables that are defined and described include family adversity factors, a family conflict tactics scale, neurologicalcognitive indicators, drug use, deviant peer associations, school deviance, sexual abuse, and frequency of arrest. Models are then presented that employ the analytic techniques of Ordinary Least Squares regression, logistic regression, and negative binomial regression. Chapter Four presents the results of multivariate analyses of these data. First, the age at which onset occurs and whether this age differs among females and males is discussed using various frequency distributions. Next, the influence of risk factors for early onset across gender is explored through various multivariate regression techniques. Finally, negative binomial regression analysis enables discussion of whether of not there are gender differences in frequency of arrest for females.

Finally, Chapter Five concludes with a summary and discussion of the current study and focuses on its purpose, design, major findings, and theoretical implications of the results. Limitations, policy implications, and suggestions for future research are also discussed. 


\section{Chapter Two}

\section{Developmental / Life-Course Criminology}

Throughout the past quarter century, research and theory in the social and behavioral sciences have embraced two main perspectives in order to better understand the nature and complexity of human behavior over time (Elder, 1994). The life-course perspective emerging from sociology focuses on the various common patterns of trajectories and turning points that people experience throughout their life course. The developmental perspective from psychology examines the stages and processes in human psycho-social development. Although both perspectives hold long-standing traditions of study within their respective disciplines, the interdisciplinary field of criminology has overlooked the developmental aspects of deviance and crime until fairly recently. Traditional avenues of criminological research compare differences across individuals that are believed to generate crime; by contrast, developmental/life-course approaches in criminology focus on changes over time within individuals that are also believed to generate crime. Developmental or life-course criminology is a broad multidisciplinary arena that weaves together ideas from many different perspectives (Benson, 2002). In particular, life-course criminology evolved through the years as a blend between developmental psychology and life-course sociology.

Developmental psychology is defined as the scientific study of psychological transformations that take place as people mature (Hogan, 2000). Areas of study in this field include psycho-physiological processes such as motor or perceptual abilities, 
language skills, abstract reasoning and understanding, moral appreciation, problemsolving, and identity construction. These topics allow answers to questions involving the differences between children and adults, and the differing processes that lead to the attainment of knowledge. Influential developmental psychologists such as Piaget, Erikson, and Kohlberg have investigated key questions regarding stages of cognitive development, psychosocial development, and moral development, respectively (Carpendale, 2000; Jenkins, 2005).

Though developmental psychology currently encompasses the entire life span, the field originally stressed the importance of early childhood through late adolescence. Moreover, developmental psychology primarily deals with psychological development in the broad sense without an explanation of how this development affects manifestation of deviant and/or criminal behaviors (LeBlanc, 1997). Unlike various criminological perspectives, developmental psychology does not necessarily include crime as an important factor. In fact, crime may not be included at all. Because of developmental psychology's original focus on early childhood and adolescent development, life-course sociologists saw the need to fill the void between development and behavior throughout the life span and thus, started their studies where developmental psychology essentially ended (Piquero and Mazerolle, 2001).

The first strong push for sociological life-course study began in the 1960's when the relationship between social changes and the lives of individuals began to take on new importance. The notion of studying the life-course first began with the growth of U.S. cities resulting from European migration. American sociologist, William I. Thomas, traced patterns in experiences across generations and promoted a "longitudinal approach 
to life history" (Volkart, 1951, p. 593). Thomas' thinking that research should focus on past, present, and future experiences of individuals (Elder, 1985) led to essays including Norman Ryder's, The Cohort as a Concept in the Study of Social Change (1965), which provided a new view of the relationship between social changes and the behavior of various age cohorts. Ryder's essay argued that differences in behavior, at varying ages, could be explained through historical changes in one's life (Ryder, 1965).

Building on this concept that changes occur throughout one's entire life, Glen Elder, a leading life-course sociologist, held that aging and development are continuous processes that change over time (Elder, 1985). According to Elder (1998), basic lifecourse elements include "multiple trajectories of individuals and their developmental implications" (p.1). Simply put, trajectories are pathways or lines of development over the life span, such as family, work, or school (Benson, 2002). Trajectories are composed of long-term patterns and sequences of behavior and experiences that are marked by change. Trajectories can be examined by combining states, such as states of health, across a person's life span. Changes, or turning points, in these states are referred to as transitions. Transitions are marked by specific life events that are "more or less abrupt" (Elder, 1985, p.32) and include events such as getting married, graduating, or acquiring a job (Sampson and Laub, 1992). These turning points result in a trajectory's change, and in turn, lead to a change in one's life course (Elder, 1985; Thornberry, 1997). How a person responds to transitions is extremely important, as one's reactions determine how their trajectory may change. The theme of transition refers to how turning points can alter life trajectories, while the theme of trajectories in life-course leads to connections regarding childhood events and adult experiences (Sampson and Laub, 1992). 
Applying these themes of transitions and turning points to the study of criminal behavior enables better understanding of why and how people begin, continue, and end criminal behaviors across the life span (LeBlanc and Loeber, 1998). This criminal career, or "longitudinal sequence of crimes committed by an individual offender," (Blumstein, Roth, \& Visher, 1986, p.12) is characterized by trajectories with elements including onset, stabilization, and desistence. Though transitions and turning points are central to most life-course theories, many theorists disagree on the specific implications of maturation as it relates to crime (Piquero and Mazerolle, 2001). Debate ensues when determining whether a pattern of crime across the life-course is categorized by continuity or change (Blumstein and Cohen, 1979; Farrington, 1986; Gottfredson and Hirschi, 1987).

Continuity is characterized by stable and continuous behavior throughout the life course. In terms of the criminological life-course perspective, continuity refers to the antisocial and/or criminal behaviors manifesting themselves in childhood that correlate to similar behaviors displayed in adulthood (Elliott, 1985; Wolfgang, Thornberry, \& Figlio, 1987). Conversely, change is characterized as behavior that starts in one direction and then moves in another direction. Views of change stress the fact that most juvenile offenders do not continue their offending patterns into adulthood (Robins, 1978). The challenge of life-course theory, then, is to explain continuity and/or change in criminal involvement across the life-course. Consequently, by borrowing from the disciplines of developmental psychology and life-course sociology, American criminologists recently began to study the links between historical age and cohort as compared to social age in the life course (Benson, 2002). 


\section{Theoretical Concepts}

Before examining the predominant concepts and theories within the criminological developmental/life-course perspective, it is necessary to mention what exactly a life-course theory is intended to explain. Most use Elder's (1985) definition to characterize the life-course as a series of "pathways through the age differentiated life span," or the interrelated paths that people take through life as they age. Accordingly, life course theories explain crime as a process, developing from childhood into adulthood (Farrington, 1986; Loeber and LeBlanc, 1990; Sampson and Laub, 1991; Moffitt, 1993).

Farrington (2003) outlines ten widely accepted conclusions that any life-course or developmental theory of criminal careers must be able to explain. These conclusions include statements regarding onset age of offending, peak ages in offending and desistence, versatility of offending, continuities in behavior from childhood through adolescence, differences between pre- and post-adolescent offending, variability in reasons for offending, and predictions of offending duration related to age of onset. Age of onset peaks between age 8 and 14, while age of desistence peaks between age 20 and 29. The earlier the age of onset, the more likely one is to have a longer period of offending. However, a majority of all offenses are committed during the late teenage years. During adolescence, a majority of offenses are committed with peers. However, after adolescence, offenses are usually committed alone. The largest percentage of crime is actually committed by a small percentage of the population. Regarding behavior, there are similarities in behavior from childhood through adolescence and then into adulthood. There are many different types of offending and antisocial behaviors. Reasons for offending change with age. In addition, different types of crimes are committed at 
different age groupings. By addressing these facts in an attempt to explain offending development, risk factors for offending, and the effects of life events on offending, life course theories are able to explain crime in very distinctive ways. (Farrington, 2003).

\section{Theoretical Importance}

Life-course theories can explain criminal behavior and delinquency in ways that other relatively static criminological theories can not. By observing offending behavior over time within the individual and taking into consideration one's life circumstances, life course theories are better able to explain both continuity and change in offending behavior through the life span. In addition, life course theories can speak to the probability of future criminal behavior and delinquency.

By studying these age-related themes over time, life-course research has found the age-crime relationship to be one of the most consistent empirical findings (Thornberry, 1997). Empirical data show that a majority of crime is committed by adolescents, who then desist as they "age out" of their late teenage years (Hirschi and Gottfredson, 1983; Farrington, 1986, 1992; Wolfgang et al., 1987; Thornberry, 1997). Because of these findings regarding adolescents, studies in criminology have tended to ignore childhood behaviors and characteristics as they relate to later adult behaviors and characteristics (Caspi, Elder, \& Bern, 1989; Farrington, 1989; Loeber and LeBlanc, 1990; Sampson and Laub, 1990). As a result of this adolescent focus, the implications of early childhood experience on both adolescent and adult development have not yet been well addressed by criminologists (Sampson and Laub, 1992).

Recently, however, developmental and life-course theories have found their way to the forefront of criminology-based research as a number of significant longitudinal 
studies have been published (Farrington, 2003). These include additional examinations of the Gluecks' study (Sampson and Laub, 1993); the Dunedin study in New Zealand (Moffitt, Caspi, Rutter, \& Silva 2001); the Causes and Correlates studies begun by the Office of Juvenile Justice and Delinquency Prevention in Denver, Pittsburgh, and Rochester (Huizinga, Weiher, Espiritu, \& Esbensen, 2003; Loeber, Farrington, Stouthamer-Loeber, Moffitt, \& Caspi, 2003; Thornberry, Lizotte, Krohn, Smith, \& Porter, 2003); the Seattle Social Development Project (Hawkins et al, 2003); and Tremblay and colleagues' (Tremblay, Masse, Vitaro, \& Dobkin, 2003) Montreal Longitudinal-Experiment study.

\section{Theoretical Evolution}

A ground-breaking study in the use of longitudinal research began in the late 1930s with the work of Glueck and Glueck (Glueck and Glueck, 1950). The Crime Causation Study: Unraveling Juvenile Delinquency recognized the importance of longitudinal data collection in regard to life-course research and delinquency. The Gluecks followed their sample of 500 delinquent boys and 500 non-delinquent boys from low socio-economic neighborhoods over a nine year period. This comprehensive data set included biological, psychological, familial, school, work, and delinquency indicators. These variables were measured through self-reports, parent reports, teacher reports, and official records (Sampson and Laub, 1993).

Another crucial project in the history of life-course research was undertaken by Wolfgang, Figlio, and Sellin during the early 1960s. Wolfgang et al., (1972) collected detailed information on over 10,000 boys from Philadelphia. Data were collected over an eight-year period in order to observe the longitudinal progression of criminal behavior. 
Original data were taken only from official records, but detailed interviews conducted when the subjects were in their mid-twenties enabled the researches to make assessments regarding offending behavior from childhood through young adulthood (Wolfgang et al., 1972).

More recently, Blumstein, Cohen, Roth, and Visher (1986) had a very notable impact in life-course criminology with their research on career criminals and criminal careers. The criminal career is defined as the "longitudinal sequence of offenses committed by an offender who has a detectable rate of offending during some period" (Blumstein et al., 1986, 2). Career criminals "commit serious offenses at high rates and over extended periods of time" (Blumstein et al., 1986, 2). The concept of the criminal career holds value to the study of life-course theory as it also stresses the importance of longitudinal data collection.

Loeber and LeBlanc (1990) were the first life-course theorists to use the term "developmental criminology" as that which focuses on continuity and within-individual changes in offending over time. Loeber and LeBlanc highlight the occurrence and timing of life circumstances in their explanations of offending. By focusing on the differences between correlates and causal factors of offending, developmental criminology adds another important facet into the life-course perspective (Loeber and LeBlanc, 1990).

Initiating the first real theoretical debate in criminology in decades, Sampson and Laub (1993) were pioneers in studying the sources of continuity and change in crime over the life span. Like Loeber and LeBlanc, they focused on within-individual changes in offending in order to explain stability and change over the life-course. 


\section{Early Antisocial Behavior}

Many researchers have focused on early onset of antisocial behaviors in children as an influential factor in later criminal behavior and delinquency. Robins (1978) was one of the first researchers to look into the correlations between antisocial behaviors (ASB) in children and adults. After collecting data on four male cohorts, results indicated that all types of antisocial behaviors studied in the children were indicators of adult antisocial behavior. Though not all male children with these behaviors carried them over into adulthood, Robins (1978) found that an overwhelming majority of the adults with ASB demonstrated these behaviors as children.

In light of the importance of age regarding early antisocial behavior, life-course criminologists propose that age is a crucial component in the understanding of delinquent behavior as well (Bartusch, Lynam, Moffit, \& Silva, 1997). Life-course theories hypothesize that prior behavior is linked to future behavior (Nagin and Farington, 1992). Accordingly, research shows that age of onset is the single best predictor of future offending (Farrington, Loeber, \& Van Kammen, 1990). "The term onset typically refers to a discrete change in state namely from nonoffender to offender" (Piquero and Chung, 2001, p.190).

Age of onset is important for several reasons. Studies have posited that early onset is a significant indicator of later offending during adolescence and adulthood (Wolfgang, 1983; Loeber and LeBlanc, 1990; Sampson and Laub, 1993). In addition, it has also been argued that the probability of one's continuance in delinquency increases as the age of onset decreases (Piquero and Chung, 2001). However, what is actually meant by the term "early" onset is not a concrete construct in the life-course perspective. Loeber and 
Farrington (2000) cite early onset as delinquent behavior occurring before age thirteen; alternatively, other studies have included age thirteen in their definition of early onset (Tremblay, Masse, Vitaro, \& Dobkin, 1995).

\section{Theoretical Perspectives of Early Onset}

In an attempt to further investigate the relationship between age and onset of offending, Moffitt (1993) suggested that antisocial behavior that begins in childhood is qualitatively different than antisocial behavior originating during adolescence. Her developmental taxonomy (1993) breaks offenders down into two categories in order to explain why one group manifests continuity in offending while the other group manifests change in offending. The first group, life-course persistent offenders (LCPs), develop antisocial behaviors early in childhood. These antisocial behaviors escalate into crime and delinquency through adolescence and into adulthood. The second group, adolescentlimited offenders (ALs), begin and end their criminal offending during adolescence.

In addition to explaining unique aspects regarding the development of offending such as onset, life-course theories also try to explain the varying risk factors that affect the development of offending (Nagin and Farrington, 1992). According to Moffitt (1993), individual neurological traits and deficits interact with an individual's social environment to produce early antisocial behavior. Neuropsychological problems result from disruption in normal brain development that leads to further psychological deficits. Neurological development can be disrupted by many factors including drug and alcohol use by the mother, poor prenatal nutrition, exposure to toxins, complications during delivery, inheritable neurological problems, and child abuse and neglect. Psychological characteristics that can be affected by neurological deficits include temperament, 
behavior, and cognitive abilities. These deficits combine with social environments to promote early antisocial behaviors for life-course persistent offenders. These deficits create stability in offending through their constant, or "contemporary" effects in the individual since early childhood and through the "cumulative continuity" that develops over time. As a result, there are fewer opportunities for a LCP offender to learn appropriate alternatives to antisocial behavior.

Unlike LCPs, adolescent-limited offenders often exhibit abrupt changes in delinquency and do not tend to show any continuity in antisocial behaviors. ALs exhibit no history of childhood antisocial behaviors. Most ALs begin offending during puberty, peak during the later teenage years, and desist by the time they reach adulthood. Whereas LCP offending behavior originates from a neurological basis, AL offending behavior originates with a maturity gap and continues with seeing the delinquency of other LCP youths. Moffitt defines this process by which ALs begin offending as "social mimicry." Models developed by Patterson and colleagues (Patterson, DeBaryshe, \& Ramsey, 1989) also show that peers are more influential for those who onset at later ages. AL youth begin to desist when they enter legitimate adult roles and can acquire desires through legitimate means. It is easier for AL offenders to desist from offending because they are not as affected by cumulative and contemporary continuity as are LCP offenders.

\section{Male Studies}

As referenced above, Moffitt (1993) has found evidence suggesting that neuropsychological problems in early childhood are a risk factor for delinquency and antisocial behaviors of male offenders. Moffitt and colleagues studied data from a battery of neuropsychological tests administered to a cohort of several hundred 13-year old New 
Zealand males. This study produced the first evidence of a prospective link between early-measured neuropsychological test scores and future offending in males. Results proved that poor neuropsychological scores at age 13 were correlated with early onset of delinquency. In addition, males with the lowest scores had the highest levels of delinquency when measured five years later. The tests predicted later delinquency measured though multiple sources including police, courts, and self-reports.

Other research examining the influence of different risk factors on early antisocial behavior includes biological and physiological determinants (Brennan et al., 1995; Raine et al., 1997). Farrington and Hawkins (1991) established that poor psychomotor skills were a factor influencing antisocial behaviors. Other risk factors that influence onset of delinquency and antisocial behavior include contextual, child, and parent risk factors. Community risk factors include access to firearms and drugs. Familial risk factors include parental mental illness or criminal behavior, negative parental attitudes, and poor family management (Preski and Shelton, 2001).

One such study that looks at a variety of risk factors regarding the development of juvenile offending is the Pittsburgh Youth Study (Loeber, Farrington, StouthamerLoeber, Moffitt, \& Caspi, 1998). Participants in this study included over 1,500 preadolescent and adolescent inner-city boys. Assessments that measured risk and protective factors and antisocial behaviors were administered over a ten-year period to three different samples of boys. Results showed that delinquency was particularly related to conduct problems, as well as measures of impulsivity, IQ, and personality. All three samples showed correlations between delinquency and child, family, and contextual explanatory variables. Having deviant peers was also a significant predictor of onset. 
Loeber et al. (1998) found that the probability of delinquency increased with increasing numbers of risk factors. Two additional studies emerged using samples from the Pittsburgh Youth Study data including Moffitt and Raine's analyses of boys from the second group of assessments. Moffitt used these assessments to look into measures including neuropsychology, impulsivity, and personality. Raine took a closer look at the boys from the second sample as well in regards to psychophysiological and biological risk factors for violence.

Another study that looks at the relationship between delinquency and personality assessments over time was conducted by Tremblay, Phil, Vitaro, and Dobkin (1994) in Canada. Over 1,000 boys from low socioeconomic schools were studied from kindergarten through age thirteen in order to test personality as a risk factor for early onset of delinquency. Personality dimensions in the assessments included anxiety, impulsivity, and reward dependence. Self-reported delinquency scales were administered to the boys when they were between the ages of ten and thirteen. High impulsivity rated by the boys' kindergarten teachers proved to be the best indicator for future self-reported delinquency. The other two personality dimensions of anxiety and reward dependence contributed to predicting future offending, though their correlations were not as strong as impulsivity.

The above studies demonstrate how early onset in males is a consistent indicator of future delinquency. However, whether the relationship between early onset and offending is a male, and not female issue, is a topic that has had little investigation (Piquero and Chung, 2001). Research has shown that deviant friends, failure at school, and leisure activities are more strongly related to conduct problems for boys than for girls 
(Stattin and Magnusson, 1995; Storvoll and Wichstrom, 2002; Werner and Silbereisen, 2003). Life-course persistent paths in males have been found to be related to dropping out of school, impulsivity, personality traits of alienation, acts of violence, and drug abuse (Moffitt, Caspi, Harrington, \& Milne, 2002; Hanlon, Bateman, Simon, O’Grady, \& Carswell, 2004). In addition, Moffitt's theory involving the interaction of neuropsychological factors and disadvantaged environments has been found to be significant risk factors for boys, but not for girls (Moffitt et al., 2002). Moffit (2002) even suggests that the issue of early onset in females may be nonexistent.

\section{Female Studies}

Because it is believed that females initiate onset at significantly later ages than males, little is known about the precursors and correlates of early female delinquency (Hipwell, Loeber, Stouthamer, Keenan, White, \& Kroneman, 2002). Most of the studies that have included females are related to various forms of delinquency, though not very many specifically look at early onset. A majority of these studies involving females point to various forms of abuse as indicators for deviant behavior and criminality.

One such study showed a significant relationship between maltreatment and delinquency in females (Widom, 1989). In her Cycle of Violence study, Widom (1989) included males and females in the sample, yet found some interesting results relating to females. Though the males had higher rates of delinquency and adult criminality than the females, Widom found that the abused or neglected females were significantly more likely to have an arrest than the control females who reported no incidences of abuse or neglect. These results regarding female arrest did not hold when involving violent crime. However, Widom explains that the long-term outcomes of abuse and neglect in young 
girls come across in different ways than in their male counterparts. She argues that females may be more likely to undergo depression because of these incidences of abuse, rather than externally display forms of violent behavior as with males. In addition, Widom points out that females are more likely to suffer sexual abuse than males, which may also affect long-term outcomes of behavior.

A further study found that sexual abuse is a unique risk factor in females (Fergusson and Woodward, 2000; Herrera and McCloskey, 2001). In addition, the onset of puberty has been shown to be more strongly related to conduct problems in females than in males (Storvoll and Wichstrom, 2002). Females have also been found to present higher rates of psychopathology, maltreatment history, and familial risk factors than males (McCabe et al., 2002). Though these findings can be explained as risk factors for delinquency, limited research has been done associated with risk factors for earlier onset in females (Gibson, Piquero, \& Tibbetts, 2001).

Physical aggression has also been looked at as an onset indicator of later delinquency and criminality. Boys are more likely to display acts of violence and physical aggression than girls (Widom, 1989; Moffitt et al., 2002). However, in relation to boys, girls are more likely to display covert as opposed to overt forms of aggressive behavior (Kazdin, 1992). In addition, a form of aggression more common to females is known as relational aggression or indirect aggression. Covert indicators for later delinquency include stealing, lying, and gossiping. Relational aggression refers to harming others through manipulation, or damage to relationships such as ostracizing peers (Tiet, Wasserman, Loeber, McReynolds, \& Miller, 2001). 
Persistent offending has been shown to begin with problem behaviors in early childhood (Gibson, Piquero, \& Tibbetts, 2001). Because of the higher prevalence of antisocial behavior in males, much less is known about the outcomes of girls with behavioral problems later on in their lives (Fergusson and Woodward, 2000). Little work has been done focusing on female onset as it relates to the number or frequency of arrests in late adolescence and early adulthood. Research on the chronic female offender is scarce and research relating chronic female offending to early onset is even scarcer (Piquero, 2000). Leve and Chamberlain (2004) found that early onset of delinquency in females leads to poorer outcomes and long-term problems. Cote, Zoccolillo, Tremblay, Nagin, and Vitaro (2001) have also suggested that onset problem behaviors in females are significant predictors of later serious delinquency. Pajer (1998) also found evidence supporting negative long-term outcomes stemming from early delinquency in females. However, she, along with many other life-course criminologists, acknowledges that there is insufficient research and data to fully understand these issues.

The current study examines gender differences in the age of onset, risk factors for onset, and the effects of early onset on frequency of future offending. Data from the second generation children involved in the Pathways to Adulthood: A Three-Generation Urban Study, 1960-1994: [Baltimore, Maryland] are used to test the following hypotheses regarding female early onset of delinquency:

\section{Hypotheses}

1. Female early onset occurs at a later age from that of male early onset.

2. Risk factors including delinquent peers, leisure activities, and behavioral and academic problems in school are predictive of early onset in males; whereas 
maltreatment, sexual abuse, and other familial problems are predictive of early onset in females.

3. Age of onset in females is predictive of future offending. 


\section{Chapter Three}

\section{Research Design and Methodology}

The data used to examine these hypotheses came from Hardy and Shapiro's study, Pathways to Adulthood: A Three-Generation Urban Study, 1960-1994: [Baltimore, Maryland]. The Pathways to Adulthood study included both prospective and retrospective data on three generations of inner-city families from Baltimore, Maryland. The prospective data were drawn from data collected during the National Collaborative Perinatal Project (NCPP). The retrospective data came from the Johns Hopkins Collaborative Perinatal Study (JHCPS). Follow-up data were collected approximately twenty-five years after the JHCPS ended.

The NCPP was a survey of pregnant women seeking prenatal care and delivery at Johns Hopkins Hospital during 1960-1964. The women were selected on the basis of the last digit of their hospital history number. This number was assigned from a central hospital file at point of first patient contact, often many years earlier. The survey looked at these first generation mothers and the children born to them during 1960-1965, coded as G2 (second generation), until the children were eight years old. Data on the second genreation included delivery room observations at birth; pediatric examinations at certain ages; developmental, neurological, language, hearing, speech, vision, motor, and physical evaluations at certain ages; psychological and behavioral profiles; and various other tests.

To qualify for the Pathways Follow-up study, second generation children had to have been born between 1960-1965 and completed the 7 and/or 8-year assessments of the JHCPS. Of the 2,694 second generation children eligible for follow-up, only 1,758 completed the 67-page, standard format questionnaire. Of the 1,758 children who 
completed the final interview, 807 were male and 951 were female. The second generation retrospective data from the follow-up study, conducted when the respondents were age 30-35, included information on aspirations, education, schooling, employment, family composition, health, housing conditions, income, legal problems, living arrangement, marriage, neighborhood characteristics at varying ages, reproductive history, social relationships, smoking, and substance abuse. In addition to the standard questionnaire, each second generation child completed a life history calendar as well.

There are limitations that must be considered when using this data set. Of the approximately 4,000 mothers enrolled in the JHCPS, 77\% were black, 22\% were white and less than $1 \%$ were from other racial groups. They were generally poor and had very low educational levels. Most of the women were employed in domestic and clerical positions.

Furthermore, the second generation follow-up interview produced only retrospective data, requiring that respondents remember correctly about the past and be willing to admit to their previous actions. The validity of self-reported criminal offenses in adult samples is generally lower than in juvenile samples (Junger-Tas \& Marshall, 1999). Self-report data are also complicated by the fact that the temporal order of negative predictors and negative outcomes is impossible to discern without prospective data collection. These facts hinder the ability to discuss causal order. Because of these sampling limitations, one must be careful when trying to generalize the data to other groups and populations. This speaks to the data's external validity as it will be difficult to generalize results to other settings. Nevertheless, the data are still very diverse in their sample characteristics and remain a representative sample for similar populations. 


\section{Dependent Variables}

Age of First Arrest, Booking, or Charge. According to Piquero and Chung (p. 190, 2001), "the term onset typically refers to a discrete change in state namely from nonoffender to offender." Onset can be measured using many different methods and factors. Onset has been operationalized in different studies as first offense, first arrest, and first conviction. Onset has been measured by official, retrospective, and prospective methods (Piquero and Chung, 2001).

It must be noted that there are different domains of offending in these data that can be used to assess age of onset. These domains vary as they relate to gender. For this analysis, only self-reported age of first arrest was used. Measurement validity issues are raised when using self-reported age of first arrest to measure onset. The results may be biased because age of first arrest does not take into account the fact that respondents may have done previous delinquent acts for which they were not arrested. Therefore, the onset age discovered in these analyses may, in fact, be older than onset age using other domains. In addition, measurement problems arise when dealing with any type of memory recall. A combination of self-reports and official arrest records would give the best results when asking about the age of first arrest. However, official arrest records are not available in the data set.

The first outcome measure in this study is age of first arrest (i.e., the age in years that the respondent was first arrest, booked, or charged by an authority of the law). At the follow-up interview, second generation children were asked a single-item question regarding the age at which they were first booked, charged, or arrested for breaking the 
law. Of the sample, $29.3 \%$ (515) reported having been booked, charged, or arrested. Of these 515 respondents, $74.4 \%$ (383) were male and $25.6 \%$ (132) were female.

\section{Independent Variables}

Independent variables include family adversity, child abuse, neurologicalcognitive, drug use, school deviance, deviant peer associations, and stand-alone risk factors including gender and frequency of arrest. These variables from the NCPP, JHCPS, and follow-up survey were chosen based on research linking their relationship to early onset of delinquency.

Family Adversity. Mothers (G1) were asked questions regarding their age, whether or not they were receiving public assistance, level of education, marital status, and income at the time of their child's (G2) birth. Mothers age was labeled young (1) if they gave birth at age seventeen or younger, or non-young $(0)$ if they gave birth at age eighteen or older. Public assistance was recoded into (0) not receiving public assistance and (1) receiving public assistance. Income was conceptualized by using Farrington and Loeber's risk factor paradigm (1999), with the lowest $25 \%$ of income indicating low income. The variable was dichotomized to differentiate those with low income (1) from those with non-low income (0). Marital status was dichotomized into (0) married when their child (G2) was born and (1) single. An educational scale was used to measure mothers educational level at the time of their child's birth, with (1) less than eighth grade through (6) graduate work.

The family adversity items (mother's age, public assistance, educational level, marital status, and income) were assessed for scalability using a principal components factor analysis (Appendix A). Among females, the family adversity items formed a single 
factor solution (eigenvalue $=1.874$ ) with loadings that ranged from .570 to .644 . Among males, these items also formed a single factor solution (eigenvalue $=1.781$ ) with loading that ranged from .495 to .720 . Final scores on the family adversity scale range from zero to ten.

Child Abuse. Family conflict tactics were conceptualized by asking how the respondents interacted with family members during disagreements. A scale of physical abuse during disagreements included whether or not the parent threatened to hit or throw something, threw something, pushed or shoved, slapped or spanked, kicked, bit, hit, beat up, burned or scalded, or threatened or used a knife or gun on the child. These items were assessed for scalability using a principal components factor analysis (Appendix B). Among females, the family-conflict tactics items formed a single factor solution (eigenvalue $=6.068)$ with loadings that ranged from .588 to .821 . Among males, these items also formed a single factor solution (eigenvalue $=4.266$ ) with loading that ranged from .461 to .708 . Six frequency indicators include never, once, twice, sometimes, frequently, and most of the time. These indicators were used as discrete variables with 0 $=$ never and $6=$ most of the time. In this additive scale, higher scores indicate higher levels of parental physical abuse. Respondent scores range from zero to forty-four. From the subsample of respondents' reporting an arrest, $82 \%$ (444) indicated receiving some form of parental physical abuse on the conflict tactics scale.

Sexual abuse is conceptualized as inappropriate sexual behavior committed by a person responsible for the care of the child. From the subsample of respondents reporting an arrest, $8.5 \%$ (44) reported being sexually abused. The sexual abuse indicator and the family conflict tactics scale were assessed for scalability using a principal components 
factor analysis (Appendix C). Among females, sexual abuse and family conflict tactics scale items formed a single factor solution (eigenvalue $=1.290$ ) with loadings of .803 . Among males, these items also formed a single factor solution (eigenvalue $=1.109)$ with loadings of .745. Final scores on the child abuse scale range from zero to 45 .

Neurological-cognitive. Neuro-cognitive factors include birth weight, verbal IQ score, WRAT reading score, WRAT arithmetic score, and WRAT spelling score. Birth weight was obtained at time of child's birth. Using the World Health Organization's standard low birth weight cutoff of $<2500$ grams, low birth weight was conceptualized by the child's weight being $<2500$ grams ( 5.8 pounds). This variable was recoded to 1 (low birth weight) and 0 (non low birth weight). From the subsample of those reporting an arrest, $13.0 \%$ (67) of respondents had a low birth weight.

Verbal IQ was assessed at age 7 using the WISC verbal IQ score. Verbal IQ was conceptualized by using Farrington and Loeber's risk factor paradigm (1999), with the lowest $25 \%$ of scores (poor scores) indicating low verbal IQ. The variable was dichotomized to differentiate those children with low verbal IQ (1) from those with nonlow verbal IQs (0). From the subsample of respondents' reporting an arrest, 21.7\% (112) had a verbal IQ in the lowest 25 percentile.

The Wide Range Achievement Test (WRAT) is a screening test that can be administered to measure the development of reading, spelling, and arithmetic skills. Also assessed at age 7, WRAT scores on each of the three tests (reading, spelling, and arithmetic) were conceptualized by using Farrington and Loeber's risk factor paradigm (1999), with the lowest $25 \%$ of scores (poor scores) indicating low WRAT scores. The 
variable was dichotomized to differentiate those children with low WRAT scores (1) from those with non-low WRAT scores (0).

The neuro-cognitive factors (birth weight, verbal IQ, and WRAT scores) were assessed for scalability using a principal components factor analysis (Appendix D). Among females, the neuro-cognitive items formed a single factor solution (eigenvalue $=$ 2.527) with loadings that ranged from .466 to .828 . Among males, these items also formed a single factor solution (eigenvalue $=2.239$ ) with loading that ranged from .303 to .779. Final scores on the neuro-cognitive scale range from zero to four.

Drug Use. Drug use is conceptualized as the extent to which the respondents indicated whether they had ever used illegal drugs including marijuana, cocaine, heroin, methadone, opiates, and glue. Involvement with these drugs was assessed by asking respondents, "Have you ever used at least one of these drugs to get high, or for other mental effects, or more than was prescribed or for longer than the doctor wanted you to?" From the subsample of respondents' reporting an arrest, 89.1\% (459) reported marijuana use; $60.2 \%$ (310) reported cocaine use; $39.6 \%$ (204) reported heroin use; $8.0 \%$ (41) reported methadone use; and $15.0 \%$ (77) reported opiate use.

Answers to questions regarding substance use have been shown to demonstrate high reliability in studies of urban and rural youth of diverse races (Starfield, 1997). However, in reviewing the validity of self-reported drug use, Magura and Kang (1996) found that marijuana was more frequently admitted than the use of other drugs. The six drugs were assessed for scalability using a principal components factor analysis (Appendix E). Among females, the drug items formed a single factor solution (eigenvalue $=4.488$ ) with loadings that ranged from .920 to .968 . Among males, these items also 
formed a single factor solution (eigenvalue $=4.701)$ with loading that ranged from .961 to .978 . The five drug variables (marijuana, cocaine, heroin, methadone, and opiates) were all separately dichotomized to differentiate those children who had used the individual drug (1) from those who had not used the individual drug (0). An additive index is employed measuring the frequency in which the respondents engaged in drug use. Final respondent scores on the additive scale range from one to ten.

School Deviance. School deviance is conceptualized as the extent to which the respondents participated in behaviors while during school hours that were against school rules. The following three items were used to create a subscale representing school deviance: getting into trouble with teachers/principal for misbehaving in grade school, getting into trouble at school for fighting, and whether or not the respondent was expelled/suspended. The items were assessed for scalability using a principal components factor analysis (Appendix F). Among females, the school deviance items formed a single factor solution (eigenvalue $=1.499$ ) with loadings that ranged from .449 to .851 . Among males, these items also formed a single factor solution (eigenvalue $=1.636)$ with loading that ranged from .676 to .780 . An additive index is employed measuring the frequency with which the respondents engaged in school deviance. Final respondent scores on the additive scale range from zero to three. From the subsample of respondents reporting an arrest (515), 40.6\% (209) reported misbehaving in school; $62.7 \%$ (323) reported fighting; and $78.8 \%$ reported being suspended or expelled.

Deviant Peer Associations. Deviant peer association is conceptualized as the extent to which respondents spent time with friends who participated in deviant (substance use) and/or criminal activity. Respondents were asked to think about close 
friends they hung around with when they were younger. They were then asked whether most, some, or none of their friends did certain activities including involvement with criminal activity, smoking, drug use, and drinking. Responses to these four questions are combined to create a scale of deviant peer association. The items were assessed for scalability using a principal components factor analysis (Appendix G). Among females, the deviant peer association items formed a single factor solution (eigenvalue $=1.893$ ) with loadings that ranged from .595 to .826 . Among males, these items also formed a single factor solution (eigenvalue $=2.300$ ) with loading that ranged from .669 to .816 . The three frequency indicators were used as discrete variables with $0=$ no friends, $1=$ some friends, and $2=$ most friends. In this additive scale, higher responses indicate a larger number of respondents' friends involved in deviant activities. Final respondent scores on the additive scale range from four to twelve.

From the subsample of respondents reporting an arrest, 28.9\% (149) reported having no friends involved in criminal activities, while $49.9 \%$ (257) and $20.6 \%$ (106) reported having some friends or most friends involved in criminal activities, respectively. From the subsample of respondents reporting an arrest, 8.9\% (46) of the sample reported having no friends who smoked, while $37.7 \%$ (194) and 53.0\% (273) reported having some friends or most friends who smoked, respectively. From the subsample of respondents reporting an arrest, 23.9\% (123) of the sample reported having no friends who used drugs, while $47.2 \%$ (243) and $27.2 \%$ (140) reported having some friends or most friends who used drugs, respectively. From the subsample of respondents reporting an arrest, $12.6 \%$ (65) of the sample reported having no friends drank alcohol, while 
$48.7 \%$ (251) and $37.7 \%$ (194) reported having some friends or most friends who drank alcohol, respectively.

Stand alone risk factors used in this study as independent variables include gender and frequency of arrest. Frequency of arrest is conceptualized as the number of times an individual was arrested during the duration of the study. The number of arrests for a single respondent varies from one arrest to thirty arrests. Table 1 presents descriptive data on the variables employed in this study.

Table 1. Description of the Data

\begin{tabular}{lrrrr}
\hline Variables & Mean & Std Dev & Minimum & Maximum \\
\hline Sex & .744 & .437 & .00 & 1.00 \\
Mom Age & .210 & .408 & .00 & 1.00 \\
Mom PubAssist & .107 & .309 & .00 & 1.00 \\
Mom Educat & 2.745 & 1.084 & 1.00 & 6.00 \\
Mom MarStat & .324 & .469 & .00 & 1.00 \\
Mom Income & .143 & .351 & .00 & 1.00 \\
Fam Con Tact & 10.922 & 9.002 & .00 & 44.00 \\
Sex Abuse & .087 & .282 & .00 & 1.00 \\
WRAT Spell & .249 & .433 & .00 & 1.00 \\
WRAT Read & .286 & .452 & .00 & 1.00 \\
WRAT Arith & .227 & .419 & .00 & 1.00 \\
Birth Weight & .130 & .337 & .00 & 1.00 \\
Verbal IQ & .219 & .414 & .00 & 1.00 \\
Drug Scale & 3.422 & 2.314 & 1.00 & 3.00 \\
School Dev & 2.715 & 1.115 & .00 & 12.00 \\
Dev Peer Assoc & 8.626 & 2.087 & 4.00 & 32.00 \\
& & & & 30.00 \\
Age of Arrest & 20.008 & 4.950 & 7.00 & \\
Freq of Arrest & 3.759 & 4.168 & 1.00 & \\
\hline
\end{tabular}

\section{Analytic Plan}

This study addresses three interrelated questions regarding female onset of delinquency. The first question asks if there is evidence of early onset of delinquency in females and, if so, at what age this onset occurs and if it differs from the age of onset in males. Second, what factors predict early onset of delinquency in females and are these factors similar to or different from those predictive of male early onset. Finally, is an 
early age of onset related to the frequency of arrest in females as it has been found to be related in males?

The first research question is answered by determining when age of onset, as defined by arrest, occurs. To address this question, both the relative frequency and cumulative frequency distribution of arrest prevalence by age for males and females is examined and compared. It is necessary to determine what constitutes evidence of "early onset" in females. For instance, the presence of a distinct group that onsets at age thirteen or younger as has been observed in males. Failing that, evidence of early onset in females could also be provided by the presence of a distinct group that onsets earlier than most other females though at a different age than what has been observed for males.

The second research question is answered by determining if there are gender differences in risk factors predicting onset. To do so, this study follows a three-step process. First, the means and standard deviations of the various independent variables are compared across different age groups for both males and females. Second, independent ttests are employed to assess whether or not there are significant differences on these factors both between and within males and females of different age groupings. The effects of gender and other explanatory factors on age of first arrest are examined in multivariate Ordinary Least Squares (OLS) regression models. Then, logistic regression models are run to determine whether risk factors for onset are similar or different across combinations of gender and age. In these logistic regression models, the dependent variable, age at first arrest, is dichotomized in the male model as (0) first arrest at age fourteen or older, and (1) first arrest at age thirteen or younger; and in the female model as (0) first arrest at age sixteen or older, and (1) first arrest at age fifteen or younger. 
To answer the third and final research question, this study examines whether or not there are gender differences in effect of early onset on the frequency of subsequent arrests using negative binomial regression. Negative binomial regression is necessary because the frequency of arrest is a highly skewed, discrete, non-negative integer (Long and Freese, 2003). Separate models are examined for males and females as this allows an examination of the effects of age of onset on the frequency of arrest across genders. A test of equality among coefficients (Brame et al., 1998) is used to estimate the statistical significance of any observed differences in coefficients between males and females. 


\section{Chapter Four}

Results

The purpose of the current section is to examine several multivariate models that predict age of first arrest, risk factors for arrest, and frequency of arrest. The following analyses speak to my primary research questions: 1) Is there evidence of early onset in females and, if so, what age does this occur and is this age different from males? 2) Are there gender differences in risk factors predicting early onset? 3) Is an early age of onset related to frequency of arrest in females? Ordinary least squares regression was utilized to model the effects of sex and other risk factors on age of first arrest. Logistic regression was applied to model the effects of age and other risk factors on "early" onset of arrest by sex. Lastly, negative binomial regression was then employed to predict frequency of arrest for both males and females.

It is first necessary to determine if "early" onset does or does not occur in females, and if so, at what age it occurs in females relative to males. First this study assesses the proportion of males and females arrested by age. As seen in Table 2, 36 $(9.5 \%)$ males in the sample were initially arrested at age thirteen or younger. Though thirteen is used as an indicator of early onset among males (Farrington, 2000), only one female in the sample was arrested at age thirteen or younger. Additionally, only five females in the sample were arrested at age fourteen or younger. Fourteen female respondents in the sample indicated an age of first arrest at age 15 or younger. However, similar in proportion to early onset males in these data, 14 (10.9\%) females in the sample 
were initially arrested at age fifteen or younger. It may very well be that there is no "early" onset among females as has been claimed by others (Silverthorn and Frick, 1999). Conversely, it may also be the case that female "early" onset occurs later than early onset in males. It may be suggested then, that females do indeed have an "early" onset, yet it occurs later than early onset in males. Furthermore, age fifteen is chosen as the cut point for "early" onset in females to also account for the typical threshold in age that often needs to be passed in order for females to be formally processed in the criminal justice system.

Table 2. Age at First Arrest

\begin{tabular}{lcccccc}
\hline & & $\leq 13$ & $\leq 14$ & $\leq 15$ & $\leq 16$ & $\geq 17$ \\
\hline \multirow{2}{*}{ MALES } & $\mathrm{N}$ & 36 & 52 & 72 & 118 & 259 \\
& $\%$ & $9.5 \%$ & $13.8 \%$ & $19.1 \%$ & $31.3 \%$ & $68.7 \%$ \\
\hline \multirow{2}{*}{ FEMALES } & $\mathrm{N}$ & 1 & 5 & 14 & 20 & 109 \\
& $\%$ & $0.8 \%$ & $3.9 \%$ & $10.9 \%$ & $15.5 \%$ & $84.5 \%$ \\
\hline
\end{tabular}

Since an 'early' age of onset in females may have been discovered, the current study was then able to assess the bivariate correlation to determine the degree of association between both age of first arrest, and frequency of arrest, and the available risk factors in these data. Results presented in Appendix H represent the associations of family adversity, child abuse, neuro-cognitive, drug use, school deviance, deviant peer associations, age of arrest, and frequency of arrest factors for both males and females. Among females, age and frequency of arrest are not significantly correlated with any of the variables.

For the males, frequency of arrest $(r=-.436, \mathrm{p}<.01)$, WRAT reading score $(\mathrm{r}=-.104, \mathrm{p}<.05)$, drug use scale $(\mathrm{r}=-.179, \mathrm{p}<.01)$, school deviance $(\mathrm{r}=-.163$, 
$\mathrm{p}<.01)$, and deviant peer associations $(\mathrm{r}=-.296, \mathrm{p}<.01)$ all yield significant inverse correlations to age of arrest; whereas, family adversity factors, sex abuse, family conflict tactics, and the other neuro-cognitive factors (i.e., WRAT spelling score, WRAT arithmetic score, birth weight, and verbal IQ) are not. Variables that positively correlate with frequency of arrest in males included their mother's marital status $(r=.158$, $\mathrm{p}<.01)$, WRAT reading $(\mathrm{r}=.243, \mathrm{p}<.01)$, WRAT arithmetic $(\mathrm{r}=.174, \mathrm{p}<.01)$, Verbal IQ $(r=.154, p<.01)$, drug scale $(r=.206, p<.01)$, school deviance $(r=.216, p<.01)$, and deviant peer association $(\mathrm{r}=.258, \mathrm{p}<.01)$. Mother educational level $(\mathrm{r}=-.218$, $\mathrm{p}<.01)$ is also correlated with frequency of arrest in males, but in an inverse relationship. The remaining family adversity factors (i.e., mother's age, public assistance, and income), sexual abuse, family conflict tactics, and WRAT spelling score did not significantly correlate with frequency of arrest.

\section{Modeling Age of First Arrest}

To answer the second research question, the effect of gender and other explanatory factors on age of first arrest are examined in multivariate Ordinary Least Squares (OLS) regression models (See Table 3). Model 1 includes sex; whereas, Models 2 and 3 are regressed by gender. In Model 1, sex has a significant effect on age of first arrest $(b=-2.889, p<.05)$. This result indicates that sex is a significant predictor of age of first arrest such that males are more likely to have an earlier onset than females. Interestingly, the child abuse indicator is significant $(b=-.326, p<.05)$, yet indicates that age of first arrest decreases with increased reports of sexual and physical abuse. The effect of deviant peers is significant $(b=-.502, \mathrm{p}<.05)$, indicating that age at first arrest decreases as the number of deviant friends increases. Among males (Model 2), deviant 
peer association remains significant $(b=-.538, \mathrm{p}<.05)$. This result again indicates that a male offender's age of first arrest decreases as their deviant peer associations increase. Among females (Model 3), none of the effects are significant in predicting age of first arrest.

Table 3. Ordinary Least Squares Regression Predicting Age of First Arrest

Variables

Model 1

Model 2

Model 3

\begin{tabular}{lcc|cc|cr}
\hline & $\underline{\mathrm{b}}$ & $\underline{\mathrm{SE}}$ & $\underline{\mathrm{b}}$ & $\underline{\mathrm{SE}}$ & $\underline{\mathrm{B}}$ & $\underline{\mathrm{SE}}$ \\
\hline Sex & $-2.195^{*}$ & .560 & & & & \\
Family Adversity & -.061 & .098 & -.030 & .117 & -.169 & .188 \\
Child Abuse & $.326^{*}$ & .160 & .222 & .223 & .379 & .245 \\
Neuro Cognitive & .018 & .071 & -.028 & .083 & .110 & .149 \\
Drug Use & -.199 & .108 & -.201 & .119 & -.120 & .275 \\
School Deviance & -.307 & .218 & -.368 & .265 & -.153 & .418 \\
Deviant Peers & $-.502^{*}$ & .125 & $-.538^{*}$ & $.143^{*}$ & -.395 & .269 \\
Constant & $27.507^{*}$ & 1.088 & $25.795^{*}$ & 1.270 & 26.034 & 2.263 \\
$\quad \mathrm{R}^{2}$ &. .143 & & .098 & & .058 & \\
$\quad \mathrm{~F}$ & $9.406^{*}$ & & $5.311^{*}$ & & .975 & \\
\hline $\mathrm{p}<.05$ & & & & & &
\end{tabular}

Comparing Across Means

The next series of analyses explore differences in the individual risk factors for early onset of arrest (mother age, mother public assistance, mother education, mother marital status, family conflict tactics, sexual abuse, WRAT spelling score, WRAT reading score, WRAT arithmetic, birth weight, verbal IQ, drug use scale, school deviance, deviant peer associations, and frequency of arrest) across males and females. Ttests are performed to examine any statistically significant differences in the means of these variables both within and between males and females by their age of first arrest grouping (i.e., "early", "normal", and "adult"). These analyses are reported in Tables 4a and $4 \mathrm{~b}$. Table $4 \mathrm{a}$ reports the means and standard deviations, while Table $4 \mathrm{~b}$ reports only statistically significant differences in these risk factors across the fifteen comparisons. 
The comparisons relevant to the current study are between early onset males (males $\leq 13$ ) and "early" onset females (females $\leq 15)$. A significantly greater proportion of "early" onset females report a prior experience of sexual abuse than do early onset males $($ mean $=.231$ vs .028 , respectively; $\mathrm{t}=-2.375, \mathrm{p}<.05)$. Conversely, early onset males report a greater number of delinquent peers than do "early" onset females $($ mean $=10.059$ vs 8.500 , respectively; $\mathrm{t}=2.370, \mathrm{p}<.05)$. That is, males are more likely to report being friends with others who were involved in criminal behaviors, drinking, smoking, and drug use. In addition, early onset males have a significantly higher mean number of arrests (mean $=7.879$ vs 2.071 , respectively; $t=3.623, p<.05$ ) than "early" onset females. Males age thirteen and younger average almost eight arrests, while females age fifteen and younger average slightly over two arrests. Though not significant, early onset males had higher mean scores on the family conflict, school deviance, and drug scales than "early" onset females. Comparisons among females reveal that "early" onset females had higher mean scores regarding mother's age and income than "normal" onset females (i.e., age 16-17). There were no significant differences among the variables between "early" and "late" onset females (i.e., $\geq 18$ ). However, "late" onset females reported higher mean scores on the family conflict tactics scale than "normal" onset females.

\section{Modeling "Early" Onset of Arrest in Males and Females}

The study now attempts to identify significant risk factors of "early" onset of arrest for males and females and determine the extent, if any, to which these risk factors are common versus gender-specific. To do so "early onset" is regressed onto several key risk factors in separate logistic regression analyses for males and females (See Table 5). 
Table 4a. Mean Comparisons by Age and Gender

\begin{tabular}{|c|c|c|c|c|c|c|c|c|c|c|c|c|}
\hline \multirow[b]{2}{*}{ Variables } & \multicolumn{2}{|c|}{$\begin{array}{l}\text { Early Onset } \\
(\text { Age } \leq 13)\end{array}$} & \multicolumn{2}{|c|}{$\begin{array}{l}\text { Normal Onset } \\
\text { (Age 14-17) }\end{array}$} & \multicolumn{2}{|c|}{$\begin{array}{l}\text { Adult Onset } \\
(\text { Age } \geq 18)\end{array}$} & \multicolumn{2}{|c|}{$\begin{array}{c}\text { Early Onset } \\
(\text { Age } \leq 15)\end{array}$} & \multicolumn{2}{|c|}{$\begin{array}{l}\text { Normal Onset } \\
\text { (Age 16-17) }\end{array}$} & \multicolumn{2}{|c|}{$\begin{array}{l}\text { Adult Onset } \\
(\text { Age } \geq 18)\end{array}$} \\
\hline & Mean & StdDev & Mean & StdDev & Mean & StdDev & Mean & StdDev & Mean & StdDev & Mean & StdDev \\
\hline MomAge & .278 & .454 & .186 & .391 & .197 & .399 & .143 & .363 & .546 & .522 & .212 & .410 \\
\hline MomPubAssist & .167 & .378 & .100 & .301 & .080 & .272 & .231 & .439 & .364 & .505 & .096 & .296 \\
\hline MomEducat & 2.639 & 1.222 & 2.768 & 1.115 & 2.848 & 1.017 & 2.385 & .870 & 2.182 & 1.079 & 2.664 & 1.137 \\
\hline MomMarStat & .417 & .500 & .288 & .455 & .289 & .454 & .308 & .480 & .455 & .522 & .385 & .489 \\
\hline MonIncome & .206 & .410 & .111 & .316 & .099 & .299 & .077 & .277 & .500 & .527 & .188 & .392 \\
\hline FamConfTact & 11.171 & 11.597 & 11.001 & 7.864 & 9.978 & 8.097 & 10.154 & 8.934 & 6.636 & 7.724 & 13.221 & 10.708 \\
\hline SexualAbuse & .028 & .167 & .036 & .186 & .045 & .207 & .231 & .439 & .182 & .405 & .221 & .417 \\
\hline WRAT Spell & .303 & .467 & .270 & .446 & .263 & .441 & .231 & .439 & .182 & .405 & .167 & .375 \\
\hline WRAT Read & .455 & .506 & .342 & .477 & .259 & .439 & .231 & .439 & .182 & .405 & .235 & .426 \\
\hline WRAT Arith & .424 & .502 & .198 & .400 & .237 & .426 & .231 & .439 & .364 & .405 & .157 & .365 \\
\hline BirthWeight & .114 & .323 & .132 & .341 & .132 & .339 & .071 & .267 & .091 & .505 & .135 & .343 \\
\hline Verbal IQ & .343 & .482 & .232 & .424 & .217 & .413 & .286 & .469 & .272 & .302 & .164 & .372 \\
\hline DrugScale & 4.606 & 2.794 & 3.869 & 2.522 & 3.049 & 2.153 & 3.583 & 2.575 & 3.091 & .467 & 3.167 & 1.923 \\
\hline SchoolDev & 2.972 & 1.183 & 3.062 & .938 & 2.702 & 1.078 & 2.357 & 1.151 & 2.546 & 2.296 & 2.330 & 1.208 \\
\hline DevPeerAssoc & 10.059 & 2.044 & 9.391 & 1.945 & 8.280 & 1.993 & 8.500 & 2.139 & 8.546 & 1.375 & 8.111 & 2.015 \\
\hline FreqArrest & 7.879 & 5.862 & 6.518 & 5.160 & 2.658 & 2.673 & 2.071 & 1.686 & 3.182 & 1.293 & 2.077 & 2.468 \\
\hline
\end{tabular}


Table 4b. Significant Differences in Individual Risk Factors by Gender

\begin{tabular}{|c|c|c|c|c|c|}
\hline & $\begin{array}{cc}\text { Male } & \text { Male } \\
\text { Early Onset } & \text { Normal Onset }\end{array}$ & $\begin{array}{c}\text { Male } \\
\text { Late Onset }\end{array}$ & $\begin{array}{c}\text { Female } \\
\text { Early Onset }\end{array}$ & $\begin{array}{c}\text { Female } \\
\text { Normal Onset }\end{array}$ & $\begin{array}{c}\text { Female } \\
\text { Late Onset }\end{array}$ \\
\hline $\begin{array}{l}\text { Males } \\
\text { Early Onset } \\
\leq 13\end{array}$ & \begin{tabular}{|l|l} 
(Early > Normal) \\
* WRAT Arith
\end{tabular} & $\begin{aligned} & \text { (Early > Late) } \\
* & \text { Dev Peer Assoc } \\
* & \text { WRAT Reading } \\
* & \text { WRAT Arith } \\
* & \text { Freq of Arrest } \\
* & \text { Drug Scale }\end{aligned}$ & $\begin{array}{c}\quad(\mathbf{F}>\mathbf{M}) \\
* \text { Sexual Abuse } \\
\quad(\mathbf{M}>\mathbf{F}) \\
* \text { Dev Peer Assoc } \\
* \text { Freq of Arrest }\end{array}$ & $\begin{array}{l}\quad(\mathrm{M}>\mathrm{F}) \\
* \text { Deviant Peer Assoc } \\
\text { * Frequency of Arrest }\end{array}$ & $\begin{array}{l}\quad(\mathrm{F}>\mathrm{M}) \\
* \text { Sexual Abuse } \\
\quad(\mathrm{M}>\mathrm{F}) \\
* \text { Deviant Peer Assoc } \\
\text { * School Deviance } \\
* \text { Verbal IQ } \\
* \text { WRAT Reading } \\
\text { * WRAT Arithmetic } \\
\text { * Frequency of Arrest } \\
\text { * Drug Scale }\end{array}$ \\
\hline $\begin{array}{c}\text { Males } \\
\text { Normal Onset } \\
14-17\end{array}$ & & $\begin{array}{l}\text { (Normal > Late) } \\
* \text { Dev Peer Assoc } \\
* \text { School Deviance } \\
* \text { Freq of Arrest } \\
* \text { Drug Scale }\end{array}$ & $\begin{array}{c}(\mathrm{F}>\mathrm{M}) \\
* \text { Sexual Abuse } \\
(\mathrm{M}>\mathrm{F}) \\
* \text { School Deviance } \\
* \text { Freq of Arrest }\end{array}$ & $\begin{array}{l}\quad(\mathrm{F}>\mathrm{M}) \\
* \text { Sexual Abuse } \\
* \text { Mom Age } \\
* \text { Mom Public Assist } \\
* \text { Mom Income } \\
\quad(\mathrm{M}>\mathrm{F}) \\
* \text { Frequency of Arrest }\end{array}$ & $\begin{array}{l}(\mathrm{F}>\mathrm{M}) \\
* \text { Sexual Abuse } \\
\quad(\mathrm{M}>\mathrm{F}) \\
* \text { Deviant Peer Assoc } \\
* \text { School Deviance } \\
* \text { Frequency of Arrest } \\
* \text { Drug Scale }\end{array}$ \\
\hline $\begin{array}{l}\text { Males } \\
\text { Late Onset } \\
\quad \geq 18\end{array}$ & & & $\begin{array}{c}\quad(\mathrm{F}>\mathrm{M}) \\
* \text { Sexual Abuse }\end{array}$ & $\begin{array}{l}\quad(\mathrm{F}>\mathrm{M}) \\
* \text { Sexual Abuse } \\
* \text { Mom Age } \\
* \text { Mom Public Assist } \\
* \text { Mom Income } \\
\quad(\mathrm{M}>\mathrm{F}) \\
* \text { Mom Education }\end{array}$ & $\begin{array}{l}(\mathrm{F}>\mathrm{M}) \\
* \text { Sexual Abuse } \\
\text { * Family Conflict Tact } \\
\text { * Mom Income } \\
\quad(\mathrm{M}>\mathrm{F}) \\
\text { * School Deviance } \\
\text { * WRAT Spelling }\end{array}$ \\
\hline $\begin{array}{c}\text { Females } \\
\text { Early Onset } \\
\leq 15\end{array}$ & & & & $\begin{array}{l}\text { (Normal > Early) } \\
* \text { Mom Age } \\
* \text { Mom Income }\end{array}$ & \\
\hline $\begin{array}{c}\text { Females } \\
\text { Normal Onset } \\
16-17\end{array}$ & & & & & $\begin{aligned} & (\text { Normal }>\text { Late }) \\
* & \text { Mom Age } \\
* & \text { Mom Public Assist } \\
* & \text { Mom Income } \\
& (\text { Late }>\text { Normal }) \\
* & \text { Family Conflict Tact }\end{aligned}$ \\
\hline
\end{tabular}


To determine whether risk factors for onset are similar or different across different age groupings and gender, models are now examined using logistic regression analyses. Because of the related proportions of age and arrest in the current study, as seen in Table2, age thirteen and below is considered early onset in males; whereas, age fifteen and below is considered early onset in females. Thirty-six male respondents were age thirteen and younger at the time of their first arrest, while 14 female respondents were age fifteen and younger. Table 5 illustrates the results of logistic regression predicting first arrest at age thirteen and younger among males and first arrest at age fifteen and younger among females.

Among early onset males, age of first arrest is a function of the neuro-cognitive scale $(b=.128, \operatorname{Exp}(b)=1.137)$ and the deviant peer association scale $(b=.434, \operatorname{Exp}(b)$ $=1.544)$. From these results, it can be determined that a one-unit increase in the neurocognitive scale indicates a $13.7 \%$ increase in the odds of being arrested at or younger than 13 years old among males. Therefore, the standardized neuro-cognitive scale (i.e., birth weight, verbal IQ, WRAT reading score, WRAT spelling score, and WRAT arithmetic score) is a predictor of first arrest in early onset males. This result indicates that lower scores on these neuro-cognitive factors is a predictor of first arrest in early onset males. Additionally, it can be determined that a one-unit increase in the deviant peer association scale indicates a $54.4 \%$ increase in the odds of being arrested at or younger than 13 years old among males. This result shows that a higher number of deviant friends is a predictor of first arrest in early onset males. Therefore, the standardized deviant peer association scale (i.e., friends who are involved in criminal activity, drinking, smoking, and using drugs) is a predictor of first arrest in early onset males. Furthermore, the male early onset 
model explains $16.3 \%$ of the variance. The same analyses described above are repeated for the early onset females (i.e., $\geq 15$ ). As see in Table 5, Model 2, none of the variables are significant.

It can be concluded from these analyses that deviant peer association remains a significant predictor of first arrest for males across various multivariate models.

Additionally, the neuro-cognitive scale is a predictor of first arrest in early onset males. Unfortunately, among females, none of the effects were significant in predicting age of first arrest.

Table 5. Logistic Regression Predicting Early Onset of Arrest by Gender

$$
\underset{(\leq 13)}{\text { Male Early Onset }} \quad \begin{gathered}
\text { Female Early Onset } \\
(\leq 15)
\end{gathered}
$$

\begin{tabular}{|c|c|c|c|c|c|c|}
\hline Variable & \multicolumn{3}{|c|}{ Model 1} & \multicolumn{3}{|c|}{ Model 2} \\
\hline & $\underline{\mathrm{b}}$ & $\underline{\mathrm{SE}}$ & $\underline{\operatorname{Exp}(b)}$ & $\underline{\mathrm{b}}$ & $\underline{\mathrm{SE}}$ & $\underline{\operatorname{Exp}(b)}$ \\
\hline Family Adversity & .120 & .083 & 1.128 & -.062 & .140 & .940 \\
\hline Child Abuse & -.076 & .167 & .927 & -.053 & .174 & .948 \\
\hline Neuro Cognitive & $.128 *$ & .062 & 1.137 & .102 & .095 & 1.108 \\
\hline Drug Scale & .142 & .084 & 1.153 & .169 & .178 & 1.184 \\
\hline School Deviance & -.177 & .133 & 1.544 & .122 & .198 & 1.130 \\
\hline Deviant Peer Assoc & $.434 *$ & .223 & .837 & .068 & .297 & 1.070 \\
\hline Constant & $-6.621 *$ & 1.321 & .001 & $-4.003 *$ & 1.756 & .018 \\
\hline$\chi^{2}$ & & $23.264 *$ & & & 3.409 & \\
\hline Nagelkerke $\mathrm{R}^{2}$ & & .163 & & & .069 & \\
\hline
\end{tabular}

$* \mathrm{p}<.05$

Modeling "Early" Onset as a Predictor of Frequency of Arrest by Gender

To answer the third and final research question, negative binomial analyses are used to determine whether or not there are gender differences in the effect of early onset on the frequency of subsequent arrests (See Table 5). Table 5 includes two models, one for males and the other for females.

For males, "early" onset is, as expected, a significant predictor of the frequency of arrest $(b=.461$, Model 1$)$; for "early" onset males the predicted mean number of arrests 
is $58.6 \%$ greater than that for "normal" and "adult" onset males. The frequency of arrest among males is also a function of the neuro-cognitive scale $(b=.049)$, school deviance scale $(b=.146)$, and deviant peer association scale $(b=.087)$. For every one-unit increase in the neuro-cognitive scale, a male offender's predicted mean number of arrests increases by $5.1 \%$. This result indicates that early onset males with lower scores on neuro-cognitive factors (i.e., birth weight, verbal IQ, and WRAT scores) have higher predicted mean numbers of arrest than "normal" or "late" onset males. In addition, for every one-unit increase in the school deviance scale, early onset males increase their predicted mean number of arrests by $15.7 \%$. This result indicates that early onset males with higher incidences of school deviance (i.e. misbehavior, fighting, and expulsion/suspension) have higher predicted mean numbers of arrest. Finally, every oneunit increase in the deviant peer association scale increases a male offender's mean number of predicted arrests by $9.1 \%$, indicating that early onset males with more deviant peers have higher predicted mean numbers of arrest.

Contrary to the study's third hypothesis, "early" onset among females is not a significant predictor of frequency of arrest. However, the frequency of arrest in females is a function of the child abuse scale $(b=-.110)$ and the drug use scale $(b=.161)$. Interestingly, a one-unit increase in the child abuse scale decreases a female's mean number of arrests by $10.4 \%$, indicating that females who report higher incidences of child abuse have lower predicted mean numbers of arrest. Additionally, for every one-unit increase in the drug scale, a female's mean number of arrests increases by $17.5 \%$. This result indicates that for "early" onset females, the predicted mean number of arrests is $17.5 \%$ greater than that for "normal" and "adult" onset females. 
Because differences between males and females are of primary interest in the current study, an analysis is performed using an equality of coefficients test (Clogg, Petkova, \& Haritou, 1995; Brame et al., 1998). These analyses are performed for every variable, even those showing insignificance in their gender-specific models. This test examines the differences between the coefficients across males and females. As expected, though insignificant as a predictor of arrest frequency in the male-only negative binomial regression analysis, the drug use scale yielded a significant $(\mathrm{z} \geq 1.96) \mathrm{z}$-score of 2.556 . In addition, though not significant in the female-only model, age of first arrest proved significant $(\mathrm{z} \geq 1.96)$ with a $\mathrm{z}$-score of 1.83 . These results indicate that both drug use and age of first arrest have significantly stronger effects for early onset males than for "early" onset females. From the negative binomial analyses, it can be concluded that early onset of arrest is a predictor for subsequent arrests in males. However, early onset of arrest is not a predictor of subsequent arrests in females.

Table 6. Negative Binomial Regression Predicting Frequency of Arrest by Gender

$$
\begin{array}{cc}
\text { Male Early Onset } & \text { Female Early Onset } \\
(\leq 13) & (\leq 15)
\end{array}
$$

\begin{tabular}{|c|c|c|c|c|c|c|c|}
\hline Variable & \multicolumn{2}{|c|}{ Model 1} & \multicolumn{3}{|c|}{ Model 2} & & \\
\hline & $\underline{\mathrm{b}}$ & SE & $\%$ & $\underline{\mathrm{b}}$ & $\underline{\mathrm{SE}}$ & $\%$ & $\underline{Z}$ \\
\hline Family Adversity & .030 & .020 & 3.1 & .020 & .035 & 2.0 & .248 \\
\hline Child Abuse & -.017 & .040 & -1.6 & $-.110 *$ & .044 & -10.4 & 1.56 \\
\hline Neuro Cognitive & $.049 *$ & .014 & 5.1 & .020 & .028 & 2.1 & .926 \\
\hline Drug Scale & .027 & .021 & 2.8 & $.161 *$ & .048 & 17.5 & 2.556 \\
\hline Dev Peer Assoc & $.087 *$ & .026 & 9.1 & .059 & .048 & 6.1 & .513 \\
\hline School Deviance & $.146^{*}$ & .048 & 15.7 & .064 & .079 & 6.6 & .887 \\
\hline "Early" Onset & $.461 *$ & .157 & 58.6 & -.161 & .301 & -14.9 & 1.83 \\
\hline Alpha & $.400 *$ & .049 & & .297 & .085 & & \\
\hline$\chi^{2}$ & & $63.21 *$ & & & $20.78 *$ & & \\
\hline Psuedo $\mathrm{R}^{2}$ & & .041 & & & .052 & & \\
\hline
\end{tabular}

\footnotetext{
$* \mathrm{p}<.05$
} 


\section{Chapter 5}

\section{Conclusion and Discussion}

The purposes of this study are threefold; (1) to explore gender differences in age of onset of arrest for delinquency, (2) to explore gender differences in the correlates of "early" onset, and (3) to explore gender differences in the effects of age of onset on the frequency of arrest using a variety of multivariate analyses. The age of onset of delinquency and antisocial behavior has been found to be a principal indicator for further delinquency as males mature through their life-course (Farrington, et al., 1990). However, even though female rates of delinquency have steadily increased over the past several years (McCabe et al., 2002), research on the age of onset, risk factors for onset, and later criminality have focused almost entirely on male populations (Piquero and Chung, 2001). Because most believe that female delinquency is only slightly varied from male delinquency, if at all, females have been generally left out of delinquency studies (Hoyt and Scherer, 1998). However, male and female populations are not necessarily similar and therefore, results from male studies of delinquency can not be generalized to females. Based on this, the current study focuses on three interrelated questions regarding female "early" onset, gender differences in risk factors of onset, and the effects of age of onset as it relates to frequency of arrest in females.

The data utilized to examine these research questions included both prospective and retrospective data collected during 1960-1994 on inner-city families from Baltimore, Maryland. Of the original sample, only 1,758 children born during 1960-1965 completed 
assessments through age 7 and/or 8, and were therefore eligible for follow-up assessments at age 30-35. Of the respondents who completed the final assessments, 515 reported the age at which they were first booked, charged, or arrested by an authority of the law. It is these 515 respondents that are included in the following bivariate and multivariate model summaries.

It was first predicted that females would display an "early" onset age of delinquency, yet at a later age from that of early male onset. An analysis assessing the proportion and corresponding age of first arrest for males and females suggested that females do indeed have an "early" onset (See Table 2), yet one that occurs later than early onset in males. From this analysis, age thirteen and below was considered early onset in males; whereas, age fifteen and below was considered "early" onset in females.

Because an "early" age of onset in females was discovered from the proportional analysis (See Table 2), it was then necessary to move on to the second research question. It was hypothesized that risk factors predicting early onset of arrest would vary across males and females. Bivariate correlations (See Appendix A) were then evaluated to determine the degree of association between both age of first arrest and frequency of arrest, and the available risk factors in these data. When exploring variable correlations among females, age of first arrest and frequency of arrest were not significantly correlated with any of the predictor variables.

In support of the current body of literature regarding early onset (Moffitt, 1993; Loeber et al., 1998), OLS regression analyses provided that sex, child abuse, and deviant peer associations all had significant effects when predicting age of first arrest. As expected, there was a unique effect of sex on age of fist arrest, even when controlling for 
all other factors. Males were also more likely than females to have an earlier age of first arrest. Additionally, as expected, deviant peers provided a significant effect in predicting first arrest in males. Among females, none of the effects were significant in predicting age of first arrest.

Though the first multivariate analyses did not support the second hypothesis, t-tests were then performed to examine any statistically significant differences in the means of the risk factors both within and between gender. In support of the current body of literature regarding early onset (Moffitt, 1993; Loeber et al., 1998; Storvoll and Wichstrom, 2002; Werner and Silbereisen, 2003), these t-tests indicated that a significantly greater proportion of early onset females report a prior experience of child abuse (i.e sexual or physical) than do early onset males; whereas, early onset males report significantly greater numbers of deviant peers than do "early" onset females.

Additionally, as expected, early onset males have a significantly higher number of arrests than do "early" onset females.

The data were again separated by gender to identify significant risk factors of "early" onset of arrest for males and females and to determine the extent, if any, to which these factors are common versus gender-specific. Logistic regression analyses provided that neuro-cognitive factors and deviant peer associations were significant predictors of early onset in males (i.e., first arrest $\leq 13$ ). These results are supported by extant literature regarding neuro-cognitive factors as early onset predictors of delinquency in males (Farrington and Hawkins, 1991; Moffitt, 1993; Raine et al., 1997), as well as deviant peer associations (Loeber et al., 1998). Conversely, support was not found for the second hypothesis regarding risk factors predicting "early" onset in females (i.e., first arrest $\leq$ 
15). Therefore, though anticipated indicators proved significant for the males when predicting first arrest $\leq 13$, none of the predictors used in the model to predict "early" onset were significant for the females when predicting first arrest $\leq 15$.

Though significant results were not found in the logistic regression analysis among females, multivariate analyses were then employed to answer the third and final research question regarding female "early" onset as a predictor of frequency of arrest. Among males, negative binomial regression analysis supports the current body of lifecourse literature. Results provide that an early age of onset, neuro-cognitive factors, and deviant peer associations are significant predictors of frequency of arrest in males (Moffitt, 1993; Piquero and Chung, 2001; Werner and Silbereisen, 2003). However, the results of the current study provide no support for the hypothesis that an "early" age of onset is related to frequency of arrest in females.

Negative binomial regression analysis found that for every one-unit increase in the drug use scale, a female's mean number of predicted arrests increased by $17.5 \%$. This result indicates that "early" onset girls who engage in higher amounts of drug use increase their predicted mean number of arrests by $17.5 \%$ more than do "normal" and "late" onset females. Interestingly, the current body of literature regarding early onset and risk factors frequently cites drug use as an indicator for males, but not so much for females. However, in support of this finding, Broidy and Agnew (1997) suggest that females are more likely than males to engage in self-destructive forms of behavior such as drug use. Another interesting finding regarding the effect of child abuse on frequency of arrest resulted in an opposite effect of what was hypothesized. Contrary to prior research (Widom, 1989; Fergusson and Woodward, 2000; Herrera and McCloskey, 
2001), child abuse had a significant negative effect when predicting frequency of arrest in females. That is, the more sexual and/or physical abuse a female reported, the lower her reported frequency of arrest.

A possible explanation for this inconsistent finding involves adjustment problems following sexual and physical abuse. Though the likelihood of adverse effects on a child's emotional and behavioral development due to child abuse has been well documented, the types of processes children use in adjustment following their abuse is quite varied (Wolfe, Gentile \& Wolfe, 1989). In addition to externalizing behaviors such as delinquency, internalizing problems such as withdrawal, depression, and post traumatic stress disorder are also common in children following abuse (Allen \& Tarnowksi, 1989; Wolfe et al., 1989; Cerezo \& Frias, 1994; Johnson and Kenkel, 1991; Wolfe, Sas, Wekerle, 1994; Spacccarelli \& King, 1995; Feiring, Taska, \& Lewis, 1998). Moreover, females are more likely than males to internalize problems (as opposed to externalize), in general. Therefore, it might be suggested that the females, age fifteen and younger, in the current study dealt with their abuse by means of internalization, rather than external displays of delinquency.

The three interrelated questions regarding female onset of delinquency in the current study include (1) whether or not there is evidence of "early" onset of delinquency in females and, if so, at what age this occurs and if this age differs from males; (2) if there are similar or different factors that predict early onset in males and females; and, (3) if an "early" age of onset is related to frequency of arrest in females. Early onset for among females was not defined at age $\leq 13$ as it has been done in males, but rather, at age $\leq 15$. However, even at age $\leq 15$, no risk factors predicted "early" onset among females. 
Additionally, "early" onset as defined in this study had no predictive value itself among females. The above conditions are both necessary within the criminological literature for "early" onset to be meaningful.

Several implications can be drawn from the above results. The variables in the current study were not significant predictors of "early" onset (as measured by arrest) in females. Furthermore, age of "early" onset was not a significant predictor of subsequent arrests in females. As stated above, both of these conditions are essential in order for the term "early" onset to be applied to females as it has already been applied to males. Research has found certain predictor variables to lower the age of antisocial and delinquent behavior in males (Moffitt, 1993; Loeber et al. 1998; Stattin and Magnusson, 2001). Additionally, research has also found that an early age of onset regarding these behaviors is a primary indicator for further antisocial behavior, delinquency, and subsequent criminality (Nagin and Farrington, 1992; Sampson and Laub, 1993). If these conditions are not met (i.e. variables that predict "early" onset and early onset predicting future delinquency and offending), the term "early" onset can not be applied to female populations.

Agnew's Strain theory can possibly be used to explain gendered responses regarding coping mechanisms in males and females. Emotional responses to strain differ across males and females. Broidy and Agnew (1997) go on to suggest that both males and females experience various forms of anger in response to strain. However, males are more likely than females to engage in various forms of crime (i.e., violent crime) in response to strain (Piquero and Sealock, 2004). Researchers propose that this response in males is the result of differences in a number of factors which include coping 
mechanisms, social support, and social controls (Giordana, Cernkovich, \& Pugh, 1986; Steffensmeier and Allan, 1996; Broidy and Agnew, 1997). On the other hand, females are more likely to respond to strain with internalizing reactions such as depression and anxiety (Leadbetter, Blatt, and Quinlan, 1995; Broidy, 2001; Cyranowski, Frank, Young, \& Shear, 2000).

While this study has shed some light on an under-researched area within criminology, there were some limitations that should be noted. First, self-reported arrest data were used in the current study. Measures of arrest may be compromised due to possible police bias and/or discrimination. There are multiple non-legal factors than can influence an officer's decision regarding whether or not to make an arrest including suspects' age and gender (Sealock \& Simpson, 1998). Feyerherm (1980) suggests that females are less likely to be arrested than males. However, girls are more likely to be arrested for minor property offenses and status offenses than their male counterparts (Chesney-Lind \& Sheldon, 1992). One study found that seriousness of police contact, the number of prior contacts with police, and whether or not the officer actually witnessed the offense had positive significant effects on female arrest (Sealock \& Simpson, 1998). Additionally, prior police contact was more important in the arrest decision for females than for males.

Other studies indicate that females are less likely to be arrested if they show signs of fear or regret when in contact with an officer, rather than signs of noncompliance or insubordination (Visher, 1983). Visher explains, however, that this type of police conduct is more often offered to white females. He goes on to suggest that black females would have higher levels of arrest because they may not display similar behaviors as the white 
females when dealing with a mostly male, white police-force. Harris (1977) also suggests that poorer females will be arrested at higher levels than middle-class females. Though the current study does not include race as an indicator, it is important to note the majority of the mothers (77\%) enrolled in the JHCPS, and thus, their children, are AfricanAmerican.

Furthermore, using arrest as a measure of "early" onset during the 1970s further limits its use as a dependent variable due to a period effect. Such a period effect is a likely artifact of events that were going on when the study participants were entering their adolescent ages. The 1970 s were a time when the juvenile justice system was taking steps to decriminalize status offenses, deinstitutionalize runaways, and divert both female and male non-serious offenders (Holden and Kapler, 1995). As such, female adolescents during this period may have experienced a particular advantage relative to males from this movement to divert, deinstitutionalize, and decriminalize the juvenile and status offenders in the form of especially low probabilities of arrest. As a result of this period effect, the data in the current study are likely to be artificially censored by the non-arrest of female offenders such that the current study's measure of "early" onset is not an accurate representation of their true onset of delinquency.

Another limitation related to operationalization is that the concept of "early" onset and what exactly is meant by that term is not a concrete issue. Reasons for determining when early onset occurs, to whom those who onset early are being compared, and who makes this distinction and why, are all questions that criminal career researchers find difficult to answer. Some studies seem to distinguish what determines early onset solely through statistical procedures in order to make data analyses more convenient. This 
however, is not necessarily a correct representation of reality. Other studies, bound by methodological limitations, define "early" onset according to the age of participants when the study began. For example, if the youngest participants in a study were 12-years old, the researcher might define early onset as any participant who indicated at the first data collection point that they had already been arrested. Regardless of the rationales provided, early-onset research is still considered relatively novel, and therefore, will continue to formulate this definition of "early" onset more concretely as research continues in this field.

In regard to other sampling limitations, the follow-up study data were collected retrospectively. Survey questions probed respondents about events in their childhood and adolescence. Respondents were expected to accurately remember past events. To the extent respondents had difficulty remembering specific events that had occurred years earlier, the quality and validity of the data is compromised. Consequently, the ability to make causal inferences and generalizations is hindered because of this methodological issue. Furthermore, the large standard errors in the multivariate analyses are very likely a function of the small cell sizes. As a result of the small sample size of those with an "early" onset, there is an increased probability of Type II error. This limitation could be alleviated with a larger sample of adolescents who exhibit "early" onset behaviors.

Lastly, the results of the current analysis are not generalizable to all segments of the population. A majority of the mothers enrolled in the JHCPS were African-American, generally poor, and indicated low educational attainment levels. Even though the data were collected on a large sample of mothers and included over 1,700 youth in the final assessment, it was not a random sample. Nevertheless, there was sufficient variability in 
the data, and the high-risk sample is consistent with populations that are of particular interests to criminologists.

In an effort to address some of these limitations, future research should concentrate on several issues. First, future research is needed to provide a more sound and defensible operationalization of early onset. Criminologists have found it especially challenging to delineate an acceptable definition of "early" onset. If "early" onset can not be concretely defined, it can not therefore, be concretely determined whether or not delinquent and/or criminal behavior falls into this group. While theoretical advances might be able to elucidate a justifiable age that constitutes early, it seems more reasonable to rely on empirical data. Perhaps statistical deviations could provide a reference, as was done in the current study. However, future researchers should consider whether other statistical deviations might be more reasonable (Raine, 1993).

Furthermore, females make up a smaller grouping of detained and adjudicated juvenile delinquents compared to males, yet female rates of delinquency have steadily increased over the past several years (McCabe et al., 2002). Increases in female arrests markedly surpassed those of males for most of the last decade (Bureau of Justice Statistics, 1999). It is necessary to better understand why female rates of delinquency are increasing at their current rates. Criminologists acknowledge that there is insufficient research and data to fully understand these issues relating to female early onset (Pajer, 1998), yet reasons for the increases of female delinquency and criminality still elude researchers. There is an absolute need to better understand early onset and the risk factors for delinquency and antisocial behavior in females. To do so, the range of behaviors needs to extend beyond just those behaviors that have been found to be typical problem 
indicators for males and include indicators including covert forms of aggressive behavior and other internalizing problems such as withdrawal, depression, and post traumatic stress disorder. 


\section{References}

Allen, D.M., \& Tarnowski, K.J. (1989). Depressive characteristics of physically abused children. Journal of Abnormal Child Psychology, 17, 1-11.

Bartusch, D. R. J., Lynam, D.R., Moffitt, T.E., \& Silva, P.A. (1997). Is age important? Testing a general versus a developmental theory of antisocial behavior. Criminology, 35(1), 13-48.

Benson, M.L. (2002). Crime and the life course: an introduction. Los Angeles, California: Roxbury Publishing Company.

Blumstein, A., \& Cohen, J. (1979). Estimation of individual crime rates from arrest records. Journal of Criminal Law and Criminology, 70, 561-585.

Blumstein, A., Cohen, J., Roth, J.A., \& Visher, C.A. (Eds.). (1986). Criminal careers and 'career criminals.’ WASHINGTON, D.C: National Academy Press.

Brame, R., Paternoster, R., Mazerolle, P., \& Piquero, A. (1998). Testing for the equality of maximum likelihood regression coefficients between two independent samples. Journal of Quantitative Criminology, 14, 245-262.

Broidy, L. (2001). A test of general strain theory. Criminology, 39, 9-35.

Broidy, L., \& Agnew, R. (1997). Gender and crime: A general strain theory perspective. Journal of Research in Crime and Delinquency, 34(3), 275-306.

Carpendale, J. I. M. (2000). Kohlberg and Piaget on stages and moral reasoning. Developmental Review, 20(2), 181-205.

Caspi, A., Elder, G.H. Jr., Bern, D.J. (1987). Moving against the world: life-course patterns of explosive children. Developmental Psychology, 23(2), 308-313.

Cerezo, M.A., \& Frias, D. (1994). Emotional and cognitive adjustment in abused children. Child Abuse and Neglect, 18, 923-932.

Chesney-Lind, M., \& Okamoto, S.K. (2001). Gender matters: patterns in girls' delinquency and gender responsive programming. Journal of Forensic Psychology Practice, 1(3), 1-28.

Chesney-Lind, M., \& Shelden, R.G. (1992). Girls, delinquency, and juvenile justice. Pacific Grove, CA: Brooks/Cole. 
Clogg, C., Petkova, E., \& Haritou, A. (1995). Statistical methods for comparing regression coefficients between models. American Journal of Sociology, 100, 1261-1293.

Cote, S., Zoccolillo, M., Tremblay, R.E., Nagin, D., \& Vitaro, F. (2001). Predicting girls' conduct disorder in adolescence from childhood trajectories of disruptive behaviors. Journal of the American Academy of Child Adolescent Psychiatry, 40(6), 678-684.

Cyranowski, J.M., Frank, E., Young, E., \& Shear, M.K. (2000). Adolescent onset of the gender difference in lifetime rates of major depression. Archives of General Psychiatry, 57, 21-27.

DiNapoli, P.P. (2003). Guns and dolls: An exploration of violent behavior in girls. Advances in Nursing Science, 46(2), 140-148.

Elder, G.H., Jr. (Ed.). (1985). Life course dynamics. New York: Cornell University Press.

Elder, G.H., Jr. (1994). Time, human agency, and social change. Social Psychology Quarterly, 57(1), 4-15.

Elder, G.H., Jr. (1998). The life-course as developmental theory. Child Development, 69(1), 1-12.

Elliot, D.S., Huizinga, D., \& Ageton, S.S. (1985). Explaining delinquency and drug use. Beverly Hills, CA: Sage.

Farrington, D.P. (1986). Age and crime. In M. Tonry \& N. Morris (Eds), Crime and Justice Review, (pp. 29-90). Chicago: University of Chicago Press.

Farrington, D.P. (1989). Early predictors of adolescent aggression and adult violence. Violence and Victims, 4, 79-100.

Farrington, D.P. (1990). Implication of criminal career research for the prevention of offending. Journal of Adolescence, 13(2), 93-113.

Farrington, D.P. (1992) Explaining the beginning, progress, and ending of antisocial behavior from birth to adulthood. In J. McCord (Ed.), Facts, Frameworks, and Forecasts. Advances in Criminological Theory, Vol. 3 (pp. 253-286). New Brunswick, NJ: Transaction Publishers.

Farrington, D.P. (2003). Developmental and life-course criminology: key theoretical and empirical issues - The 2002 Sutherland Award Address. Criminology, 41(2), 221-255. 
Farrington, D.P., \& Hawkins, J.D. (1991). Predicting participation, early onset, and later persistence in officially recorded offending. Criminal Behavior and Mental Health, 1(1), 1-33.

Farrington, D.P., Loeber, R., \& Van Kammen, W.B. (1990). Long-term outcomes of hyperactivity-impulsivity-attention deficit and conduct problems in childhood. In L.N. Robins and M. Rutter (Eds.), Straight ad devious pathways from childhood to adulthood (pp. 62-81). New York: Cambridge University Press.

Feiring, C., Taska, L., \& Lewis, M. (1998). The role of shame and attributional style in chikldren's and adolescents' adaptation to sexual abuse. Child Maltreatment, 3, 129-142.

Fergusson, D.M., \& Woodward, L.J. (2000). Educational, psychosocial, and sexual outcomes in girls with conduct problems in early adolescence. Journal of Child Psychology and Psychiatry, 41(6), 779-792.

Feyerherm, W. (1980). Gender differences in delinquency: quantity and quality. In L.H. Bowker (Ed.), Women and Crime in America (pp. 82-92). New York: Macmillan.

Gibson, C.L., Piquero, A.R., \& Tibbetts, S.G. (2000). Assessing the relationship between maternal cigarette smoking during pregnancy and age at first police contact. Justice Quarterly, 17(3), 519-542.

Gibson, C.L., Piquero, A.R., \& Tibbetts, S.G. (2001). The contribution of family adversity and verbal IQ to criminal behavior. International Journal of Offender Therapy and Comparative Criminology, 45(5), 574-592.

Gibson, C.L., \& Tibbetts, S.G. (2000). A biosocial interaction in predicting early onset of offending. Psychological Reports, 86, 509-518.

Giordano, P., Cernkovich, S.A., \& Pugh, M.D. (1986). Friendships and delinquency. American Journal of Sociology, 91(5), 1170-1202.

Glueck, S., \& Glueck, E.T. (1990). Unraveling juvenile delinquency. Cambridge, MA: Harvard University Press.

Gottfredson, M., \& Hirschi, T. (1987). The methodological adequacy of longitudinal research on crime. Criminology, 25(3), 581-614.

Hanlon, T.E., Bateman, R.W., Simon, B.D., O’Grady, K.E., \& Carswell, S.B. (2004). Antecedents and correlates of deviant activity in urban youth manifesting behavioral problems. The Journal of Primary Prevention, 24(3), 285-309.

Harris, A.R. (1977). Sex and theories of deviance: toward a functional theory of deviant typescripts. American Sociological Review, 42, 3-16. 
Herrera, V. M., \& McCloskey, L. A. (2001). Gender differences in the risk for delinquency among youth exposed to family violence. Child Abuse and Neglect, 25, 1037-1051.

Hirschi, T., \& Gottfredson, M. (1993). Age and the explanation of crime. American Journal of Sociology, 89(3), 522-584.

Hogan, John D.; In: Encyclopedia of Psychology, Vol. 3. pp. 9-13. Washington, DC: American Psychological Association, 2000.

Holden, G.A., \& Kapler, R.A. (1995). Deinstitutionalizing status offenders: a record of progress. Journal of the Office of Juvenile Justice and Delinquency Prevention, 2(2), 3-11.

Hoyt, S., \& Scherer, D.G. (1998). Female juvenile delinquency: misunderstood by the juvenile justice system, neglected by social science. Law and Human Behavior, 22(1), 81-107.

Hipwell, A. E., Loeber, R., Stouthamer-Loeber, M., Kennan, K., White, H. R., \& Kroneman, L. (2002). Characteristics of girls with early onset disruptive and antisocial behavior. Criminal Behavior and Mental Health, 12, 99-118.

Huizinga, D., Weiher, A.W., Espiritu, R., \& Esbensen, F. (2003). Delinquency and crime: some highlights from the Denver Youth Study. In T.P Thornberry \& M.D. Krohn (Eds.), Taking Stock of Delinquency: An Overview of Findings from Contemporary Longitudinal Studies (pp. 47-91). New York: Kluwer/Penum.

Jeglum Bartusch, D.R., Lynam, D.R., Moffitt, T.E., \& Silva, P.A. (1997). Criminology, 35(1), 13-48.

Jenkins, S.M., Buboltz, W.C. Jr., \& Schwartz, J.P. (2005). Differentiation of self and psychosocial development. Contemporary Family Therapy: An International Journal, 27(2), 251-261.

Johnson, B.K., \& Kenkel, M.B. (1991). Stress, coping, and adjustment in female adolescent incest victims. Child Abuse and Neglect, 15, 293-305.

Junger Tas, J., \& Marshall, H.I. (1999). The self-report methodology in crime research. In M. Tonry (Ed.), Crime and Justice: A Review of Research (pp. 291-367). Chicago, IL: University of Chicago Press.

Keenan, K., \& Shaw, D. (1997). Developmental and social influences on young girls' early problem behavior. Psychological Bulletin, 121(1) 95-113. 
Lahey, B.B., Moffitt, T.E., \& Caspi, A. (Eds.). (2003). Causes of conduct disorder and juvenile delinquency. New York: The Guilford Press.

Laub, J.H. (2004). The Life-Course of Criminology in the United States: The American Society of Criminology 2003 Presidential Address. Criminology, 42(1), 1-21.

Leadbeater, B.J., Blatt, S.J., Quinlan, D.M. (1995). Gender-linked vulnerability to depressive symptoms, stress, and problem behaviors in adolescents. Journal of Research on Adolescence, 5, 1-29.

Le Blanc, M., \& Loeber, R. (1998). Developmental criminology updated. In M. Tonry (Ed.), Crime and Justice, Vol. 23 (pp. 115-198). Chicago: University of Chicago Press.

Leve, L. D., \& Chamberlain, P. (2004). Female juvenile offenders: defining an earlyonset pathway for delinquency. Journal of Child and Family Studies, 13(4), 439452.

Lewis, D.O., Yeager, C.A., Cobham-Portorreal, C.S., Klein, N., Showalter, C., \& Anthony, A. (1991). A follow-up of female delinquents: Maternal contributions to the perpetuation of deviance. Journal of American Academy of Child and Adolescent Psychiatry, 30(2), 197-201.

Loeber, R., \& Faqrington, D.P. (1999). Serious and violent juvenile offenders: Risk factors and successful interventions. Thousand Oaks, CA: Sage.

Loeber, R., \& Farrington, D.P. (2000). Young children who commit crime: Epidemiology, developmental origins, risk factors, early interventions, and policy implications. Development and Psychopathology, 12, 737-762.

Loeber, R., Farrington, D.P., Stouthamer-Loeber, M., Moffitt, T.E., \& Caspi, A. (1998). The development of male offending: Key findings from the first decade of the Pittsburgh Youth Study. Studies on Crime and Crime Prevention, 7(2), 141-171.

Loeber, R., Farrington, D.P., Stouthamer-Loeber, M., Moffitt, T.E., Caspi, A., White, A. W., Wei, E.H., \& Beyers, J.M. (2003). The development of male offending: Key findings from form fourteen years of the Pittsburgh Youth Study. In T.P. Thornberry and M.D. Krohn (Eds.), Taking Stock of Delinquency: An Overview of Findings from Contemporary Longitudinal Studies (pp. 93-136). New York: Kluwer/Plenum.

Loeber, R., \& LeBlanc, M. (1990). Toward a developmental criminology. ?375-473.

Loeber, R., Wung, P., Keenan, K., Giroux, B., Stouthamer-Loeber, M., \& Van Kammen, W.B. (1993). Developmental pathways in disruptive child behavior. Development and Psychopathology, 5, 101-132. 
Long, J., \& Freese, S. (2003). Regression models for categorical dependent variables using STATA. College Station, TX : STATA Press

Mason, W.A., \& Windle, M. (2001). Delinquency risk as a function of number of early onset problem behaviors. International Journal of Offender Therapy and Comparative Criminology, 45(4), 436-448.

Mazerolle, P., Brame, R., Paternoster, R., Piquero, A., \& Dean, C. (2000). Onset age, persistence, and offending versatility: comparisons across gender. Criminology, 38(4), 1143-1172.

McCabe, K. M., Lansing, A. E., Garland, A., \& Hough, R. (2002). Gender differences in psychopathology, functional impairment, and familial risk factors among adjudicated delinquents. Journal of American Academy of Child and Adolescent Psychiatry, 41(7), 860-867.

Moffitt, T.E. (1993). Adolescent-limited and life-course persistent antisocial behavior: A developmental taxonomy. Psychological Review, 100, 674-701.

Moffitt, T.E. (2001). Adolescent-limited and life-course persistent antisocial behavior. In A. Piquero \& P. Mazerolle (Eds.), Life-course criminology: Contemporary and classic readings. Samford, CT: Wadsworth/Thomson Learning.

Moffitt, T.E., \& Caspi, A. (2001). Childhood predictors differentiate life-course persistent and adolescent-limited antisocial pathways among males and females. Development and Psychopathology, 13, 355-375.

Moffitt, T.E., Caspi, A., Dickson, N., Silva, P., \& Stanton, W. (1996). Childhood-onset versus adolescent-onset antisocial conduct problems in males: Natural history from ages 3 to 18 years. Development and Psychopathology, 8, 399-424.

Moffitt, T. E., Caspi, A., Harrington, H., Milne, B. J. (2002). Males on the lifecourse persistent and adolescence-limited antisocial pathways: follow up at age 26. Developmental Psychopathology, 14, 179-207.

Moffitt, T.E., Caspi, A., Rutter, M., \& Silva, P.A. (2001). Sex differences in antisocial behavior. United Kingdom: Cambridge University Press.

Moffitt, T.E., Lynam, D.R., \& Silva, P.A. (1994). Neuropsychological tests predicting persistent male delinquency. Criminology, 32(2), 277-289.

Nagin, D.S., \& Farrington, D.P. (1992). The onset and persistence of offending. Criminology, 30, 111-140. 
Nagin, D.S., Farrington, D.P., \& Moffitt, T.E. (1995). Life-course trajectories of different types of offenders. Criminology, 33(1), 111-124.

Pajer, K. A. (1998). What happens to "bad" girls? A review of the adult outcomes of antisocial adolescent girls. American Journal of Psychiatry, 155(7), 862-870.

Patterson, G.R., DeBaryshe, B.D., \& Ramsey, E. (1989). A developmental perspective on antisocial behavior. American Psychologist, 44(2), 329-335.

Patterson, G.R., Forgatch, M.S., Yoerger, K.L., \& Miller, M.S. (1998). Variables that initiate and maintain an early-onset trajectory for juvenile offending. Development and Psychopathology, 10, 531-547.

Piquero, A.R. (2000). Assessing the relationships between gender, chronicity, seriousness, and offense skewness in criminal offending. Journal of Criminal Justice, 28, 103-115.

Piquero, A.R. (2001). Testing Moffitt's neuropsychological variation hypothesis for the prediction if life-course persistent offending. Psychology, Crime \& Law, 7, 193215.

Piquero, A.R. \& Brezina, T. (2001). Testing Moffitt's account of adolescence-limited delinquency. Criminology, 39(2), 353-370.

Piquero, A. R., \& Chung, H. L. (2001). On the relationships between gender, early onset, and the seriousness of offending. Journal of Criminal Justice, 29, 189-206.

Piquero, A.R., \& Mazerolle, P. (Eds.). (2001). Life course criminology: contemporary and classic readings. Belmont, $\mathrm{CA}$ : Wadsworth.

Piquero, A.R., \& Tibbetts, S. (1999). The impact of pre/perinatal disturbances and disadvantaged familial environment in predicting criminal offending. Studies on Crime and Crime Prevention, 8(1), 52-70.

Piquero, N.L., \& Sealock, M.D. (2004). Gender and general strain theory: A preliminary test of Broidy and Agnew's gender/GST hypotheses. Justice Quarterly, 21(1), 125-158.

Preski, S., \& Shelton, D. (2001). The role of contextual, child, and parent factors in predicting criminal outcomes in adolescence. Issue in Mental Health Nursing, 22, 197-205.

Raine, A. (1993). The psychopathology of crime: criminal behavior as a clinical disorder. San Diego, CA: Academic Press. 
Raine, A., Brennan, P., \& Mednick, S.A. (1997). Interaction between birth complications and early maternal rejection in predisposing individuals to adult violence: Specificity to serious, early-onset violence. American Journal of Psychiatry, 154(9), 1265-1271.

Richters, J.E., \& Cicchetti, D. (1993). Toward a developmental perspective on conduct disorder. Development and Psychopathology, 5, 1-4.

Robins, L.N. (1978). Sturdy childhood predictors of adult antisocial behavior: replications form longitudinal studies. Psychological Medicine, 8, 611-622.

Ryder, N.B. (1965). The cohort as a concept in the study of social change. American Sociological Review, 30, 843-861.

Sampson, R.J., \& Laub, J.H. (1990). Crime and deviance over the life course. American Sociological Review, 55(5), 609-27.

Sampson, R.J., \& Laub, J.H. (1992). Crime and deviance in the life course. Annual Review of Sociology, 18, 63-84.

Sampson, R.J., \& Laub, J.H. (1993) Crime in the making: Pathways and turning points through life. Cambridge, MA: Harvard University Press.

Sealock, M.D., \& Simpson, S.S. (1998). Unraveling bias in arrest decisions: the role of juvenile offender type-scripts. Justice Quarterly, 15(3), 427-257.

Silverthorn, P., \& Frick, P.J. (1999). Developmental pathways to antisocial behavior: The delayed-onset pathway in girls. Development and Psychopathology, 11, 101-126.

Spaccarelli, S. (1995). Measuring abuse stress and negative cognitive appraisals in child sexual abuse: validity data on two new scales. Journal of Abnormal Child Psychology, 23, 703-727.

Stattin, H., \& Magnusson, D. (1995). Onset of official delinquency: its co-occurrence in time with educational, behavioral, and interpersonal problems. British Journal of Criminology, 35(3), 417-449.

Steffensmeier, D. \& Allan, E. (1996). Gender and crime: toward a gendered theory of female offending. Annual Review of Sociology, 22, 459-487.

Storvoll, E. E., \& Wichstrom, L. (2002). Do the risk factors associated with conduct problems in adolescents vary according to gender? Journal of Adolescence, 25, 183-202. 
Taylor, J., Iacono, W.G., \& McGue, M. (2000). Evidence for a genetic etiology of earlyonset delinquency. Journal of Abnormal Psychology, 109(4), 634-643.

Tibbetts, S. G., \& Piquero, A. R. (1999). The influence of gender, low birth weight, and disadvantaged environment in predicting early onset of offending: a test of Moffitt's interactional hypothesis. Criminology, 37(4), 843-877.

Tiet, Q. Q., Wasserman, G. A., Loeber, R., McReynolds, L. S., \& Miller, L. S. (2001). Developmental and sex differences in types of conduct problems. Journal of Child and Family Studies, 10(2), 181-197.

Thornberry, T.P. (1997). Introduction: some advantages of developmental and life-course perspectives for the study of crime and delinquency. In T.P. Thornberry (Ed.), Developmental Theories of Crime and De3linquency (pp. 1-10). New Brunswick, NJ: Transaction Publishers.

Thornberry, T.P., Lizotte, A.J., Krohn, M.D., Smith, D.A., \& Porter, P.K. (2003). Causes and consequences of delinquency: findings from the Rochester Youth Development study. In T.P. Thornberry and M.D. Krohn (Eds.), Taking Stock in Delinquency: An Overview of Findings from Contemporary Longitudinal Studies (pp. 11-46). New York: Kluwer/Plunem.

Tremblay, R.E., Phil, R.O., Vitaro, F., \& Dobkin, P.L. (1994). Predicting early onset of male antisocial behavior from preschool behavior. Archives of General Psychiatry, 51(9), 732-739.

Tremblay, R.E., Masse, L.C., Vitaro, F., \& Dobkin, P.L. (1995). The impact of friends' deviant behavior on early onset of delinquency: longitudinal data from 6 to 13 years of age. Development and Psychopathology, 7, 649-667.

Tremblay, R.E., Vitaro, F., Nagin, D., Pagani, L., \& Seguin, J.R. (2003). The Montreal Longitudinal and Experimental study: rediscovering the power of descriptions. In T.P. Thornberry and M.D. Krohn (Eds.), Taking Stock in Delinquency: An Overview of Findings from Contemporary Longitudinal Studies (pp. 205-254). New York: Kluwer-Plenum.

U.S. Bureau of Justice Statistics (1999). Criminal offending statistics. U.S. Departments of Justice, Office of Justice Programs: Washington, D.C. Retrieved April 9, 2006.

Visher, C.A. (1983). Gender, police arrest decisions, and notions of chivalry. Criminology, 21, 5-28. 
Volkart, E.H. (Ed.), Social Behavior and Personality: Contributions of W.I. Thomas to Theory and Research. New York: Social Science Research Council.

Werner, N.E., \& Silbereisen, R. K. (2003). Family relationship quality and contact with deviant peers as predictors of adolescent problem behaviors: The moderating role of gender. Journal of Adolescent Research, 18(5), 454-480.

Widom, C.S. (1989). The cycle of violence. Science, 244, 160-166.

Wolfe, D.A., Sas, L., \& Wekerle, C. (1994). Factors associated with the development of posttraumatic stress disorder among child victims of sexual abuse. Development and Psychopathology, 6, 165-181.

Wolfe, V.V., Gentile, L, Wolfe, D.A. (1989). The impact of sexual abuse on children: A PTSD formulation. Behavior Therapy, 20, 215-228.

Wolfgang, M.E., Figlio, R.M., \& Sellin, T. (1972). Delinquency in a birth cohort. Chicago: University of Chicago Press.

Wolfgang, M.E., Thornberry, T.P., \& Figlio, R.M. (1987). From boy to man, from delinquency to crime. Chicago: University of Chicago Press.

Zoccolillo, M. (1993). Gender and the development of conduct disorder. Development and Psychopathology, 5, 65-78. 
Appendices 
Appendix A: Family Adversity Factor Analysis by Gender Family Adversity Items - FEMALES Factor Loading

1. Mother's age at time of child's birth .644

2. Mother receiving public assistance at time of child's birth

3. Mother's educational level at time of child's birth $-.581$

4. Mother's marital status at time of child's birth

5. Mother's income at time of child's birth .570

Eigenvalue $=$ 1.874

Variance $=$ 37.5

2. Mother receiving public assistance at time of child's birth

3. Mother's educational level at time of child's birth

4. Mother's marital status at time of child's birth

5. Mother's income at time of child's birth

$\begin{array}{ll}\text { Eigenvalue }= & 1.781 \\ \text { Variance }= & 35.6\end{array}$


Appendix B: Family Conflict Tactics Factor Analysis by Gender Family Conflict Tactics Scale Items - FEMALES Factor Loading

1. Threaten to hit or throw things .659

2. Throw, smash, hit, kick things .770

3. Throw something at child .816

4. Push, grab, or shove child .772

5. Slap or spank child .588

6. Kick, bite, or hit child with fist .821

7. (Try to) or hit child with something .780

8. Beat up child .787

9. Burn or scald child .671

10. Threaten child with knife or gun .752

11. Use knife or gun on child .718

Eigenvalue $=\quad 6.068$

Variance $=$

55.2 
Appendix B: (Continued)

\begin{tabular}{lc}
\hline Family Conflict Tactics Scale Items - MALES & Factor Loading \\
\hline 1. Threaten to hit or throw things & .694 \\
2. Throw, smash, hit, kick things & .643 \\
3. Throw something at child & .699 \\
4. Push, grab, or shove child & .689 \\
5. Slap or spank child & .493 \\
6. Kick, bite, or hit child with fist & .708 \\
7. (Try to) or hit child with something & .695 \\
8. Beat up child & .659 \\
9. Burn or scald child & .461 \\
10. Threaten child with knife or gun & .538 \\
11. Use knife or gun on child & .492 \\
& Variance = \\
\hline
\end{tabular}


Appendix C: Child Abuse Factor Analysis by Gender Child Abuse Items - FEMALES Factor Loading

1. Sexual Abuse $\quad .803$

2. Family Conflict Tactics Scale $\quad .803$

Eigenvalue $=\quad 1.290$

Variance $=\quad 64.5$

Child Abuse Items - MALES $\quad$ Factor Loading

1. Sexual Abuse $\quad .745$

2. Family Conflict Tactics Scale $\quad .745$

Eigenvalue $=\quad 1.109$

Variance $=\quad 55.4$ 
Appendix D: Neuro-Cognitive Factor Analysis by Gender

\begin{tabular}{lc}
\hline Neuro-Cognitive Items - FEMALES & Factor Loading \\
\hline 1. WRAT Spelling score & .780 \\
2. WRAT Reading score & .828 \\
3. WRAT Arithmetic score & .803 \\
$\begin{array}{l}\text { 4. Birth weight } \\
\text { 5. Verbal IQ }\end{array}$ & .466 \\
$\quad$ Eigenvalue $=$ & .609 \\
$\quad$ Variance & $=$ \\
& 50.5
\end{tabular}

\begin{tabular}{|c|c|}
\hline Neuro-Cognitive Items - MALES & Factor Loading \\
\hline 1. WRAT Spelling score & .711 \\
\hline 2. WRAT Reading score & .799 \\
\hline 3. WRAT Arithmetic score & .779 \\
\hline 4. Birth weight & .303 \\
\hline 5. Verbal IQ & .628 \\
\hline Eigenvalue $=$ & 2.239 \\
\hline Variance $=$ & 44.7 \\
\hline
\end{tabular}


Appendix E: Drug Use Factor Analysis by Gender \begin{tabular}{ll}
\hline Drug Use Items - FEMALES Factor Loading \\
\hline
\end{tabular}

$\begin{array}{ll}\text { 1. Marijuana } & .964 \\ \text { 2. Cocaine } & .961 \\ \text { 3. Heroin } & .968 \\ \text { 4. Methadone } & .922 \\ \text { 5. Opiates } & .920\end{array}$

Eigenvalue $=\quad 4.488$

Variance $=\quad 89.8$

\begin{tabular}{|c|c|c|}
\hline Drug Use Items & - MALES & Factor Loading \\
\hline 1. Marijuana & & .978 \\
\hline 2. Cocaine & & .964 \\
\hline 3. Heroin & & .967 \\
\hline 4. Methadone & & .961 \\
\hline \multirow[t]{3}{*}{ 5. Opiates } & & .978 \\
\hline & Eigenvalue = & 4.701 \\
\hline & Variance $=$ & 94.0 \\
\hline
\end{tabular}


Appendix F: School Deviance Factor Analysis by Gender

\begin{tabular}{|c|c|}
\hline School Deviance Items - FEMALES & Factor Loading \\
\hline 1. Frequently misbehave in school & .851 \\
\hline 2. In trouble for fighting at school & .757 \\
\hline 2. Ever suspended/expelled from school & .449 \\
\hline Eigenvalue $=$ & 1.499 \\
\hline Variance $=$ & 50.0 \\
\hline
\end{tabular}

\begin{tabular}{|c|c|}
\hline School Deviance Items - MALES & Factor Loading \\
\hline 1. Frequently misbehave in school & .676 \\
\hline 2. In trouble for fighting at school & .755 \\
\hline 2. Ever suspended/expelled from school & .780 \\
\hline Eigenvalue $=$ & 1.636 \\
\hline Variance $=$ & 54.5 \\
\hline
\end{tabular}


Appendix E: Deviant Peer Association Factor Analysis by Gender Deviant Peer Association Items - FEMALES Factor Loading

1. Friends who are involved in crime .595

2. Friends who smoke .657

3. Friends who use drugs .652

4. Friends who drink .828

Eigenvalue $=$ 1.893

Variance $=$ 47.3

Deviant Peer Association Items MALES Factor Loading

1. Friends who are involved in crime .669

2. Friends who smoke .816

3. Friends who use drugs .752

4. Friends who drink .788

Eigenvalue $=\quad 2.300$

Variance $=\quad 57.5$


Apendix H: Bivariate Correlations by Sex (Females Above the Main Diagonal / Males Below the Main Diagonal)

\begin{tabular}{lccccccccc}
\hline & AgeArrest & FreqArr & MomAge & MomPub & MomEdu & MomMar & MomInc & FamConTact & SexAbuse \\
AgeArrest & - & -.093 & -.064 & -.114 & .022 & .043 & .045 & .162 & .071 \\
FreqArrest & $-.436^{* *}$ & - & .124 & .139 & -.040 & -.009 & .024 & -.045 & -.040 \\
MomAge & .011 & .090 & - & .143 & $-.333^{* *}$ & $.439^{* *}$ & .107 & .068 & .057 \\
MomPubAs & -.085 & .057 & .086 & - & $-.255^{* *}$ & .136 & $.311^{* *}$ & .058 & .120 \\
MomEduca & .062 & $-.218^{* *}$ & $.219^{* *}$ & $-.217^{* *}$ & - & $-.179^{*}$ & -.090 & -.161 & .004 \\
MomMarStat & -.051 & $.158^{* *}$ & $.425^{* *}$ & $.257^{* *}$ & $-.101^{*}$ & - & $.286^{* *}$ & .048 & $.181^{*}$ \\
MomIncome & -.033 & .081 & .075 & $.158^{* *}$ & $-.145^{* *}$ & $.211^{* *}$ & - & -.062 & $.190^{*}$ \\
FamConTact & -.014 & .042 & $.155^{*}$ & .017 & -.020 & .046 & .020 & - & $.290^{* *}$ \\
SexAbuse & .079 & -.057 & -.001 & -.021 & -.063 & -.017 & -.078 & $.109^{*}$ & - \\
WRAT Sp & .038 & .094 & .098 & $.150^{* *}$ & $-.173^{* *}$ & .048 & .025 & -.062 & -.034 \\
WRAT Re & $-.104^{*}$ & $.243^{* *}$ & .089 & $.202^{* *}$ & $-.181^{* *}$ & .090 & .067 & -.078 & -.019 \\
WRAT Ar & -.007 & $.174^{* *}$ & .062 & .094 & $-.160^{* *}$ & .087 & -.028 & $-.130^{*}$ & -.021 \\
BirthWeight & .004 & .023 & $.110^{*}$ & .032 & -.067 & .080 & .050 & -.020 & -.001 \\
VerbalIQ & -.051 & $.154^{* *}$ & .095 & -.048 & $-.155^{* *}$ & .025 & .081 & -.076 & .015 \\
DrugScale & $-.179^{* *}$ & $.206^{* *}$ & .053 & .014 & $-.111^{*}$ & -.044 & -.011 & .094 & $.207^{* *}$ \\
SchDev & $-.163^{* *}$ & $.216^{* *}$ & -.070 & .019 & $-.126^{*}$ & .010 & -.054 & $.114^{*}$ & .043 \\
DevPeer & $-.296^{* *}$ & $.250^{* *}$ & .041 & .028 & -.052 & .076 & .010 & $.161^{* *}$ & .077 \\
\hline
\end{tabular}

$* * \mathrm{p}<.01$

$* \mathrm{p}<.05$ 
Appendix H: (Continued)

\begin{tabular}{|c|c|c|c|c|c|c|c|c|}
\hline & WRATSp & WRATRe & WRATAr & BirthWeight & VerbalIQ & DrugScale & SchDev & DevPeer \\
\hline AgeArrest & .061 & .035 & -.079 & .126 & -.091 & .004 & -.006 & -.093 \\
\hline FreqArrest & .062 & .109 & .143 & -.046 & .139 & $.218 * *$ & .048 & $.284 * *$ \\
\hline MomAge & .127 & .001 & .114 & -.041 & .063 & .150 & .063 & .145 \\
\hline MomPubAs & .105 & .096 & $.267 * *$ & .122 & .098 & .120 & .147 & .110 \\
\hline MomEduca & $-.277 * *$ & $-.207 *$ & $-.284 *$ & $-.264 * *$ & $-.185^{*}$ & -.036 & $-.183^{*}$ & -.103 \\
\hline MomMarStat & .094 & -.015 & .077 & .132 & .067 & .157 & .165 & .029 \\
\hline MomIncome & -.009 & .057 & .088 & .094 & -.078 & $.226^{*}$ & .069 & .046 \\
\hline FamConTact & .087 & .053 & .029 & .091 & -.055 & .153 & $.217 * *$ & $.259 * *$ \\
\hline SexAbuse & .008 & .073 & -.003 & .080 & -.064 & $.360 * *$ & .130 & $.244 * *$ \\
\hline WRAT Sp & - & $.559 * *$ & $.454 * *$ & $.255^{* *}$ & $.402 * *$ & .071 & $.330 * *$ & -.043 \\
\hline WRAT Re & $.468 * *$ & - & $.633 * *$ & $.294 * *$ & $.303 * *$ & .073 & $.203^{*}$ & .024 \\
\hline WRAT Ar & $.414 * *$ & $.497 * *$ & - & $.243 * *$ & $.386 * *$ & .046 & $.250 * *$ & .060 \\
\hline BirthWeight & $.153 * *$ & $.155^{* *}$ & .096 & - & .126 & -.087 & $.220^{*}$ & .033 \\
\hline VerbalIQ & $.222 * *$ & $.356 * *$ & $.391 * *$ & $.118^{*}$ & - & -.107 & .155 & .094 \\
\hline DrugScale & -.041 & .035 & .095 & -.054 & -.033 & - & .107 & $.480 * *$ \\
\hline SchoolDev & .009 & .075 & .099 & -.040 & -.002 & $.227 * *$ & - & $.269 * *$ \\
\hline DevPeer & -.075 & -.023 & -.052 & $-.120 *$ & -.015 & $.349 * *$ & .137 & - \\
\hline
\end{tabular}

$* * \mathrm{p}<.01$

$* \mathrm{p}<.05$ 